\title{
El Derecho Internacional Privado y el DERECHO COMUNITARIO
}

\author{
International Private LAW AND Communitarian LAW
}

\section{Abelardo Posso Serrano*}

Resumen: El Derecho Internacional Privado se justificó en una época en la que los sistemas legales de los Estados Nacionales buscaban una forma de extenderse en sus ámbitos y competencias. Este afán compartido provocó precisamente el conflicto entre las leyes nacionales, que se hizo menor cuando surgió la novedosa concepción de "comunidad internacional", pero no fueron suprimidos los relativismos nacionales. Un nuevo ordenamiento jurídico empezó a conformarse, luego, con el avance de los procesos de integración. Las normas comunitarias cuentan con mecanismos necesarios para ser aplicables, aún cuando los Estados quisieran tratar de ignorarlas o de cumplirlas de manera relativa.

Palabras clave: Derecho Internacional privado, derecho comunitario, relativismos, ordenamientos jurídicos de alcance universal, competencias comunitarias

Abstract: Private international law is justified at a time when the legal systems of nation states seeking a way to extend their areas and competencies. This desire led to the conflict between national laws,

* Diplomático de carrera, Embajador de la República del Ecuador, con amplia experiencia en diplomacia multilateral. Ha sido Embajador Representante Alterno del Ecuador ante el Consejo de Seguridad de las Naciones Unidas. Embajador ante los Países Bajos y Embajador en Australia y Nueva Zelanda. Desde el 2005 es profesor de la Universidad de Los Hemisferios (Ecuador), en Derecho y Ciencias Políticas. abelardop@uhemisferios.edu.ec 
which grew smaller as did the novel concept of "international community", but did not suppress national relativism. A new law began to settle, then, with the progress of the integration process. Community laws have mechanisms to be applied, even when states would try to ignore them or to fulfill a relative way.

Key words: Private international law, community law, relativism, universal laws, competence of communities

Fecha de recepción: 20-03-2010

Fecha de aceptación: 30-04-2010

\section{CONSIDERACIONES PREVIAS}

Los trataditas clásicos del Derecho Internacional Privado, cuando enfocan la temática y los contenidos del mismo por el camino del Derecho Natural; si lo hacen desde la óptica del derecho privado de los extranjeros; sea que hubieran puesto énfasis en las competencias de los Estados; o inclusive si hubieren adoptado la noción "conflicto de leyes", muy difundida en el sistema jurídico anglo-sajón, suelen señalar que las dificultades de la disciplina, el poco avance de las instituciones y la existencia misma del conflicto, cuando se trata de determinar qué leyes deben aplicarse en una relación jurídica que han llevado a cabo personas particulares de distintos Estados o nacionales de un Estado pero para que los efectos de la relación tengan lugar en otro u otros Estados, se debe a una estrecha e incuestionable relación del Derecho Internacional Privado con la Comunidad Internacional.

El concepto moderno de Comunidad Internacional empieza a delinearse en la primera posguerra del siglo pasado, cuando es posible que algunos puedan descubrir un vínculo con el inicio del deterioro de los "Estados Nacionales"; esto es cuando se plantean, 
primero tímidamente y luego, ya en la segunda posguerra, de manera abierta, que la soberanía no corresponde a los Estados, puesto que es propia de la Comunidad Internacional, que, para explicar mejor la noción, prestaría porciones de la misma a los Estados, para que la administren, pero que por ser prestada la soberanía, la Comunidad Internacional conservaría la facultad de pedir cuentas a los Estados sobre la forma cómo administraron la porción de soberanía que recibieron (Pesantes García, 1977).

La facultad de la Comunidad Internacional de pedir cuentas a los Estados es precisamente la justificación para que pueda exigirse el cumplimiento de las promesas que hicieron los Estados de acoger y respetar los principios de Derecho Internacional, recogidos principalmente en los dos intentos mayores de consolidar la institucionalización de la Comunidad Internacional: esto es, para constituir la fallida Liga de las Naciones; y cuando se pusieron las bases para la todavía vigente Organización de las Naciones Unidas.

El Estado que, a pesar de haberse comprometido a hacerlo (se compromete cuando presenta una solicitud formal de ingreso a las Naciones Unidas - para dejar por el momento a un lado el incumplido compromiso que asumieron los miembros de la Liga de las Naciones-) empieza a actuar en desacuerdo con los principios fundamentales recogidos en la Carta, ya da lugar a que la Comunidad Internacional llamé su atención. De continuar con la inconducta o de agravarla, hasta violar esos principios, daría lugar a que la Comunidad Internacional organizada aplique sanciones al Estado infractor, sanciones éstas que podrían incluso llegar al uso de la fuerza.

Otra muy importante consideración previa, podría plantearse en la evidente vinculación del Derecho Internacional Privado con la importancia concedida a los llamados Estados Nacionales. En efecto, antes de la vigencia en el mundo de las instituciones del Estado Nacional, los sistemas jurídicos imperantes, para citar el más evidente, el Derecho Romano, poca atención pusieron para 
establecer las reglas para resolver los conflictos entre las leyes provinciales y locales (Mangas Martín \& Liñán Nogueras, 2009).

Incluso después de la caída del Imperio romano, no podría encontrarse un origen claro del Derecho Internacional Privado en el Derecho Romano-Germano, porque éste se solía aplicar en base a la "personalidad", esto es a la vinculación de las normas con las personas, de manera tal que cualquiera que fuese el lugar de su residencia, el individuo aplicaba la ley de su nación.

La multiplicidad de leyes que se van estableciendo a lo largo de los siglos XVI, XVII y XVIII dan lugar a que esas leyes pretendan cubrir todos los posibles casos en los que los individuos puedan verse envueltos y pretenden comprender todas las leyes aplicables a cada caso. Las competencias que se desea comprender, no sólo se extienden a los ámbitos nacionales, porque muchos Estados, como los conocemos actualmente, todavía no se habían conformado como tales; por ello, las competencias que se plantean eran también de las ciudades y de otras poblaciones importantes, muchas de ellas muy próximas.

En consecuencia, los pilares del Derecho Internacional Privado, bajo la óptica de la configuración de la concurrencia de leyes nacionales que pueden aplicarse a una misma relación entre individuos, se empiezan a establecer en la segunda mitad del siglo XIX, en Europa, por el florecimiento de los Estados Nacionales, particularmente de Francia y Alemania. Son precisamente tratadistas franceses y alemanes los que plantean eventuales colisiones, conflictos, de las leyes de los distintos Estados, que por sus pretendidas competencias, ordinariamente deben aplicarse a sus nacionales (Larrea Holguín, 1962).

Conjuntamente con la noción generalizada de los ámbitos propios de la leyes está inmerso el concepto de Estado Nacional, como legítimo detentador de la competencia, incuestionada e incuestionable, de aplicar sus leyes en todos los actos y en todas las relaciones que ocurran dentro de sus territorios nacionales. Las 
colisiones probables, entonces, son precisamente de las leyes nacionales, frente a relaciones que incumban a dos o más Estados.

La noción de exclusividad de la competencia de un Estado Nacional, empieza a resquebrajarse cuando se pretende, en la aplicación de las leyes, ir más allá de los confines nacionales; esto es cuando se plantea la extraterritorialidad de algunas leyes de ciertos Estados, cuyos nacionales podrían provocar situaciones que involucren las competencias de otro u otros Estados, mucho más frecuentemente que otros nacionales de otros Estados, quizás por la fluidez de las relaciones, por ejemplo comerciales, de los primeros, en actos que jurídicamente podrían justificar la aplicación de la ley del Estado Nacional del que son originarios, con prioridad a la aplicación de otra ley, asimismo nacional, no obstante a que se admite y se reconoce que los efectos de esos determinados actos sobrepasaron los límites estrictamente nacionales (Alonso García, 1997).

El "conflicto" ocurre precisamente por la renuencia de un Estado Nacional a reconocer que no tiene las mismas competencias soberanas que las del Estado que pretende extender su ley nacional más allá de sus correspondientes confines nacionales.

Existe en consecuencia un claro parentesco entre las competencias nacionales para aplicar sus leyes y la igualdad jurídica de los Estados, aún cuando este principio se aplique mejor a las relaciones entre Estados, no entre particulares, pero si como un compromiso aceptado tanto para la convivencia civilizada entre Estados, como para buscar fórmulas para superar los conflictos de leyes nacionales, que pueden ocurrir cuando los actos y las relaciones de los individuos alcanzan una dimensión internacional, es decir cuando van más allá de las competencias estrictamente nacionales.

En consecuencia con lo anterior, una posibilidad cierta de superar los conflictos de leyes está en la asunción de compromisos entre los Estados, para establecer reglas que se acepta que se 
apliquen para ordenar los actos y las relaciones de los individuos, cuando tales actos y relaciones comprometan las competencias de dos o más Estados Nacionales.

Los tratadistas suelen mencionar la ley, la jurisprudencia y los tratados internacionales como fuentes del Derecho Internacional Privado, pero me parece que cuando de conflictos de leyes nacionales se trata, la vía convencional es entonces la más adecuada para superar tales conflictos o colisiones de las leyes nacionales. Mientras más extendidos sean los convenios internacionales, es decir los compromisos de los Estados para aplicar ciertas reglas, más se habría progresado en el ámbito del Derecho Internacional Privado, mucho más que si hubieran proliferado leyes nacionales y mucho más también si hubiera pretendido desarrollar el Derecho Internacional Privado en base a una eventual abundante jurisprudencia (Arjona Colomio, 1954).

Reconocida la mayor importancia de los convenios internacionales, con el propósito de seguir la misma línea de deducción, podría afirmarse que los convenios que para determinar las reglas se hubieren hecho entre dos Estados Nacionales, significarían un menor aporte al Derecho Internacional Privado que los convenios multilaterales, aquellos que convocan la participación de un mayor número de Estados Nacionales. Mientras mayor sea ese número, más importante será el aporte para el desarrollo de la disciplina, porque el acuerdo multilateral podría incluso ser aplicado, de manera supletoria, por Estados no comprometidos oficialmente en el acuerdo.

En términos prácticos, la Carta de la Liga de las Naciones y la Carta de las Naciones Unidas son convenios multilaterales, que prevén un desarrollo del concepto de Comunidad Internacional. En el ámbito propio de esta comunidad puede ser concebido también el Derecho Internacional Privado, que empieza a crecer precisamente cuando deja de ser tan severa la concepción de la soberanía exclusiva y excluyente de los Estados Nacionales. 
Entonces, es la concepción de Comunidad Internacional la que abre las posibilidades para establecer compromisos exigibles a todos los Estados, bajo los condicionamientos de otros principios fundamentales como el de la igualdad jurídica de todos los Estados, la no intervención y la renuncia a la amenaza o al uso de la fuerza, por ejemplo; y asimismo, esta concepción de Comunidad Internacional es el camino adecuado para que las reglas que el Derecho Internacional Privado aspiraba a extender por varios Estados, se hagan una realidad.

La mayor extensión de los ámbitos de las reglas para superar los eventuales conflictos de leyes nacionales en relaciones internacionales entre particulares, se consigue con mayor facilidad si los Estados Nacionales acuden voluntariamente a un modelo ideado para que fuere internacional, supranacional o, si se quiere, a un modelo que no sea creado y conformado dentro de competencias domésticas, pero que si fuere posible acomodar a las situaciones nacionales que escapen de los límites ordinarios del Estado Nacional.

Se fundamentaría la concurrencia de los Estados Nacionales a un modelo internacional, porque cada Estado aportó para la creación de ese modelo o debido a que existe una corriente que los Estados Nacionales no pueden evitar; de cualquier forma, la voluntad soberana de los Estados se salva porque medió un compromiso soberano, aún cuando no se quisiera admitir la concepción ideal, mencionada anteriormente, de conceder a la Comunidad Internacional una soberanía propia, de la que se desprenderían las porciones de soberanía que administran los Estados.

Muy posiblemente, la extensión del modelo internacional, en cada campo específico de relación internacional, podría conseguir la adopción generalizada de un sistema, que idealmente tendría que terminar por ser único. A esa uniformidad se orientan los esfuerzos que los Estados hacen para regularizar el comercio 
internacional, por ejemplo, o el tráfico aéreo, o la navegación marítima.

Las metas en unos determinados campos, en este amplísimo panorama de relación internacional, es posible que sean más fáciles de alcanzar que otras, porque sobre esos campos es que son más frecuentes los reclamos de los Estados acerca del valor de su soberanía nacional. Las reglas relativas a la migración internacional, por ejemplo, otra área propia del Derecho Internacional Privado, son mucho más complicadas de unificar porque los Estados Nacionales se resisten a internacionalizarlas, debido a que las vinculan con la protección de los derechos de los nacionales, con su seguridad y con el bienestar social o porque pueden llegar a ser Estados de atracciones masivas de migrantes, las que exigen obligaciones que superan las posibilidades reales de los Gobiernos de esos Estados de destino o porque pueden las prácticas migratorias, contrariar políticas nacionales restrictivas.

Es menester, por lo anotado, considerar las distancias entre los ideales para establecer una auténtica Comunidad Internacional, que en su última versión incluso haría innecesario el Derecho Internacional Privado, y los intereses y objetivos de los Estados Nacionales, que del auge que tuvieron, en cuanto se refiere a la aplicación severa de las leyes nacionales, empezaron a dejar crecer a la Comunidad Internacional, con mayor evidencia en la segunda posguerra a mediados del siglo pasado, pero que actualmente, superada la Guerra Fría, parece que tratan de revitalizarse.

\section{ORDENAMIENTOS JURÍDICOS DE ALCANCE INTERNACIONAL}

Los esfuerzos de la Comunidad Internacional para, a través de convenciones especializadas, poner en vigencia universal algunos ordenamientos jurídicos esenciales, si puede decirse, desde un punto de vista de aplicación práctica de esos Ius Humani, v. 2 (2010/11), p. 78 
ordenamientos, que entre otras ventajas evitan los conflictos entre leyes nacionales de ámbitos similares al del ordenamiento universal y al hacerlo, al evitar las colisiones entre las leyes de los Estados Nacionales, hacen innecesario que los jueces ante una eventual "litis" deban acudir a las reglas concertadas entre esos Estados Nacionales para superar los conflictos.

El Derecho Internacional Privado es en esencia ese conjunto de reglas convencionales (bilateral o multilateralmente concebidas) para que los jueces ante quienes fue sometida una cuestión, puedan superar los conflictos por la confrontación de diferentes sistemas jurídicos nacionales.

Los tratadistas clásicos de Derecho Internacional Privado precisamente concordaban en que se hacía menester ampliar las concertaciones entre Estados Nacionales, para que la aplicación de las reglas convencionales para superar conflictos de leyes, sean cada vez de mayor aplicación universal.

Es cierto que estas reglas convencionales son particularmente válidas para dirimir cuestiones planteadas entre particulares que proyecten sus relaciones a ámbitos internacionales y casi por excepción tales reglas convencionales incluyen a los Estados, como sujetos de derecho, a no ser que la relación que haya provocado la confrontación de leyes sea una que caiga dentro del sector privado; esto es cuando el Estado actúa como un particular, situación ésta que cada día en el mundo contemporáneo es más usual.

También debe admitirse que los indicados esfuerzos de la Comunidad Internacional se han demostrado preferente, no exclusivamente, en el sector público, esto es en la esfera del Derecho Internacional Público.

No obstante las consideraciones previas, es incuestionable que muchas actividades privadas que solían provocar conflictos en los ámbitos internacionales, se han visto aliviadas cuando ha entrado en vigencia una particular convención universal específica, para tratar sobre materias que en las concepciones 
clásicas del Derecho Internacional Privado eran susceptibles de provocar esos conflictos de leyes.

La finalización de la II Guerra Mundial, por ejemplo, trajo la posibilidad real de aplicar leyes de común aceptación universal, para juzgar y sancionar a particulares que cometieron crímenes de guerra. Los tribunales especiales de Nuremberg y Tokio precisamente intentaron aplicar esas leyes comúnmente aceptadas como válidas, aún cuando no existía en ese entonces un código penal internacional que establezca delitos y penas. No obstante, en ausencia de tal código, bastó un acuerdo entre los países aliados, que ganaron la guerra, para poner en vigencia un ordenamiento penal internacional. Los tribunales penales internacionales posteriores hicieron ver a la Comunidad Internacional que si es posible establecer un estatuto de aplicación mundial, precisamente por una convención multilateral que ponga en marcha el derecho común. La Corte Penal Internacional, aparte de los tribunales penales especiales para la antigua Yugoslavia, para Ruanda y para Sierra Leona, ya permite la aplicación de una sola ley universal para juzgar delitos contra los derechos humanos y de lesa humanidad.

En otras materias propias de convenciones multilaterales promovidas por la Organización de Naciones Unidas puede ser que se note con menor evidencia que lo que ocurre con el derecho penal internacional, el "alivio" de la carga de conflictos que distingue al Derecho Internacional Privado, pero de cualquier manera resultará incuestionable el avance de la humanidad en Derecho del Mar; en Derecho Mercantil Internacional; en Derecho de los Tratados; en las Convenciones Internacionales sobre Derechos Humanos (incluso los derechos políticos que sirvieron de fundamento para los conflictos clásicos sobre nacionalidad y derechos de los extranjeros); en Derecho Internacional Humanitario; Derecho Aéreo Internacional; Propiedad Intelectual, etc. para citar las esferas consideradas tradicionalmente como las más propensas para provocar los conflictos de leyes. 
Es importante señalar que en esa materia penal internacional y en otras también extendidas a ámbitos internacionales, no puede decirse con la misma propiedad que la que se presenta en la esfera del Derecho Internacional Privado, que hayan servido para aliviar la carga de responsabilidad propia del Derecho Comunitario, porque este derecho si tiene contenidos, lo que no ocurre con el Derecho Internacional Privado que se compone de reglas para acudir a contenidos jurídicos nacionales.

El derecho comunitario hace suyas también las disposiciones universales sobre estas materias específicas y al adoptarlas como propias compartirá competencias con los Estados Nacionales para la promulgación de leyes y reglamentos que sirvan para aplicar correctamente los compromisos asumidos al suscribir cada una de esas convenciones universales sobre materias específicas.

Por otra parte, la existencia de un derecho de aplicación universal no es extraño para la comunidad que ha desarrollado su normativa de derecho, aplicable precisamente a esa comunidad, con la suficiente protección de la misma comunidad, por ella misma, y con el apoyo subsidiario de los Estados Nacionales que la componen, para hacer valer esas normas universales frente a otros Estados y a otras comunidades. Esto sería parte de la ampliación de la competencia de la comunidad y de los derechos y facultades de los particulares de esa comunidad, prevista como principio fundamental del derecho comunitario.

\section{OTROS EJEMPLOS DE LA AMPLIACIÓN DE LAS ÓRBITAS DEL DERECHO CON LA UNIVERSALIZACIÓN}

\subsection{Derecho internacional del mar}

El ámbito propio de este derecho comprende aspectos de soberanía de los Estados sobre el mar; jurisdicciones nacionales; y derechos y obligaciones de los Estados, pero al tratar más 
específicamente sobre los límites de las zonas marinas, abarca el ordenamiento que se seguirá para la explotación de los recursos marinos y los recursos minerales en la plataforma continental de los Estados, actividades éstas que aún cuando fueren exclusivamente desarrolladas por los Estados (que no lo son) éstos lo harían asumiendo las actividades propias del sector privado, otra órbita prevista dentro del Derecho Internacional Privado, no muy frecuente pero si posible.

Las medidas previstas para la navegación, para la protección y conservación del medio marino y los procedimientos para la solución de controversias, ciertamente que si "alivian" la carga de conflictos que distingue el ámbito clásico del Derecho Internacional Privado.

\subsection{Derecho mercantil internacional}

En la órbita que proponen los Estados, con su participación en la Organización Mundial de Comercio -OMC- el Derecho Mercantil Internacional sería el conjunto de normas relativas a los comerciantes en ejercicio de actividades defendidas, promovidas, protegidas por los Estados o, en casos muy particulares, desarrolladas por ellos mismos, en todas las manifestaciones de comercio, con la particularidad de que tales actividades comerciales deberían, por mandato de los Estados Miembros de la OMC, propender a un comercio mundial libre, sujeto a ordenamientos comunes para regular la actividad económica, impedir los desequilibrios, evitar la competencia desleal y la utilización del comercio como instrumento de presión internacional, etc.

Aparte de las normas que viene aplicando la OMC, los Estados Miembros de las Naciones Unidas participan en las actividades de la UNCITRAL, la Comisión de las Naciones Unidas para la unificación del Derecho Mercantil Internacional, que promueve una progresiva armonización y unificación de las normas jurídicas de los Estados sobre comercio internacional. Las 
tareas de los Estados, a través de la UNCITRAL, crea estándares y reglas para que sean adoptadas por los Estados Miembros. La armonización y unificación de las leyes mercantiles, sumadas a los estándares y a las reglas de aplicación (reglamentos de aplicación de las normas) alivian evidentemente la carga del Derecho Internacional Privado clásico.

La propuesta que se viene desarrollando a nivel mundial, es la de crear un Derecho Económico Internacional, sobre la base de una experiencia de la humanidad que encuentra sus orígenes en la Edad Media y en el Renacimiento, precisamente para evitar los conflictos entre las leyes nacionales o para disminuir interpretaciones nacionales extremas, de aplicación internacional insuficiente, como la llamada extraterritorialidad de ciertas leyes mercantiles nacionales de potencias comerciales.

\subsection{Convenciones internacionales sobre derechos humanos}

Existen pocas materias más, que no sean sobre Derechos Humanos, que puedan resultar pruebas más evidentes de la evolución del derecho en beneficio de los seres humanos individualmente considerados, más allá de las conveniencias y de los intereses de sus propios Estados.

En efecto, la defensa y los esfuerzos por la extensión mundial de los Derechos Humanos van mucho más allá de las competencias de los Estados Nacionales, cuyas eventuales conductas perjudiciales a los derechos fundamentales de los individuos pueden ser señaladas por otros Estados, sin constituir intervencionismos ilegales, y progresivamente, cada vez en mayor medida, por los particulares perjudicados.

Los derechos de las mujeres, de los niños, de los ancianos, de las minorías nacionales, e inclusive los derechos de los extranjeros para participar en ciertas actividades políticas esenciales, forman parte de los contenidos de los Derechos Humanos que van alcanzado mayor difusión internacional y que se imponen ante los ordenamientos jurídicos nacionales, que los 
irrespeten o vulneren, en materias consideradas hace muy pocos años como privativas de las competencias jurídicas domésticas.

Los compromisos soberanamente asumidos por los Estados Nacionales al suscribir las convenciones y los llamados pactos internacionales sobre Derechos Humanos adoptan principios de Derecho Natural de aplicación universal, en esferas que vienen creciendo progresiva y sistemáticamente. No resulta extraño concebir, en esa línea de consecuencias, las denuncias que pronto podrán formularse contra Estados Nacionales que violen derechos humanos esenciales de convivencia en paz y en democracia, desde puntos de vista internos, de cada Estado, y de la comunidad internacional.

\subsection{Derecho internacional sobre propiedad intelectual}

La concepción misma de las normas convenciones multilaterales sobre propiedad intelectual, parte de la posibilidad legal de provocar una variación esencial en el derecho de propiedad general, previsto en las legislaciones nacionales.

Más de una veintena de tratados internacionales sobre propiedad intelectual aseguran que prácticamente todo el mundo se acoja a una similar normativa sobre la materia, que evidentemente trasciende de la aplicación territorial de los Estados Nacionales y en consecuencia se establece una protección similar a los derechos de propiedad intelectual, la misma que por ser compartida evita un eventual conflicto entre sistemas nacionales.

La protección internacional de la propiedad intelectual actúa como un eficaz mecanismo de presión internacional para que un Estado renuente o de comportamiento elástico, sea aislado de la comunidad internacional por no someterse a mecanismos jurídicos similares, también comúnmente aceptados, de respeto a un ordenamiento internacional, que es un factor de seguridad jurídica; y para la solución de litigios entre particulares.

Las normas y procedimientos sobre propiedad intelectual comparten plenamente las características con el derecho 
comunitario, al proponer una sola norma de común aplicación y al plantear la igualdad de derechos entre cada país miembro y lo que es fundamental entre los nacionales de otro país. Como añadidura, las codificaciones de la normativa sobre derechos de autor y derechos conexos, establecen las responsabilidades morales y patrimoniales que se derivan de los derechos de propiedad intelectual e inclusive varios aspectos procesales que suelen seguirse, para protegerlos.

\subsection{Derecho humanitario internacional}

En el paradójico propósito de "humanizar" la guerra, concebida como un último recurso de derecho de los Estados, los individuos son incuestionablemente los objetivos de las protecciones previstas por el Derecho Internacional Humanitario, puesto que las obligaciones para humanizar la guerra se dedican precisamente a los Estados envueltos en conflictos bélicos.

Esa protección mínima que en casos de guerra deben tener los individuos, primero se concertó entre los Estados para que envuelvan a sus soldados de tierra y mar; luego se amplió para que la protección recaiga en las poblaciones civiles que resultan víctimas de las acciones de guerra; y la tendencia de la protección es evidente que seguirá extendiéndose hasta reconocer todos los derechos de los individuos frente a la guerra, incluso el derecho fundamental de "objeción de conciencia", que en muchas legislaciones nacionales ya se admite como suficiente para exonerar a los particulares de verse forzados por los Estados a involucrarse en acciones de guerra, como soldados.

Las esferas propias del Derecho Humanitario Internacional se vinculan con los Derechos Humanos y con el Derecho Penal Internacional, particularmente.

\subsection{Derecho de los tratados}

Si bien el ordenamiento jurídico que se unifica con la Convención Internacional sobre el Derecho de los Tratados cae 
esencialmente en la órbita del Derecho Internacional Público, la aplicación de los principios comúnmente aceptados para poner en plena aplicación los fundamentos de las Naciones Unidas; la preservación de la paz y la seguridad internacionales; y la erradicación de la amenaza o del uso de la fuerza en las relaciones entre Estados, implican una serie de derechos y facultades de los individuos que viven en los Estados.

Por otra parte, las eventuales delimitaciones de fronteras, involucran a los nacionales de los Estados, como ocurrió en los célebres casos recogidos por la historia a principios y a mediados del siglo pasado con los naturales de Alsacia y Lorena, "pasados" a Alemania y devueltos luego a Francia (un caso típico registrado en los anales del Derecho Internacional Privado).

Los derechos individuales y patrimoniales de los particulares afectados por cambios en las conformaciones de los Estados son evidentes, por lo que la regulación de los conceptos, los principios, las formas y los procedimientos para que los Estados acuerden esos cambios territoriales, ofrece una estabilidad que consolida también los derechos de los particulares, especialmente de aquellos que habitaban en zonas geográficas reclamadas recíprocamente como suyas, por parte de dos o más Estados.

\subsection{Corolario}

Otros ordenamientos universales, como los referidos a Derecho Aéreo, Derecho Espacial, otras normas concertadas para la administración de la Antártida, para el uso de frecuencias radioeléctricas y en fin materias tan estrechamente vinculadas a los individuos como el Derecho del Trabajo, la seguridad social incluida, han ido en permanente avance, probablemente no tan constante como las limitaciones a esos mismos derechos impuestas por razones particulares de los Estados, en materias relativas a la seguridad y a las migraciones, por ejemplo. 
Las contracorrientes evidentes de estos avances para internacional las conductas jurídicas de los Estados Nacionales han sido en los últimos años más bien coyunturales y queda la esperanza, fundamentada, de que aún cuando fuere el único mérito colateral de la globalización, las concepciones propias de esos buenos intentos por conseguir crear normas jurídicas de aplicación universal y el paulatino fortalecimiento del derecho comunitario, harán cada día menos útiles a la reglas concertadas para reenviar un sistema jurídico nacional, aparte de que éstos mismos ordenamientos nacionales, cada vez serán más similares.

El interés y la conveniencia para los Estados Nacionales y el involucramiento participativo de las sociedades civiles, justifican y explican las usuales "cesiones de soberanías nacionales", que van creando un panorama de relación internacional entre los particulares, que quizás no fue ni siquiera imaginado por los tratadistas clásicos del Derecho Internacional Privado.

\section{Primeras Consideraciones relativas al Derecho Internacional Privado}

No existen contenidos de cuerpos legales que pueda decirse que corresponden al Derecho Internacional Privado, puesto que los contenidos tendrían que ser los cuerpos legales de los Estados Nacionales.

Las diferencias entre las leyes nacionales, serán más evidentes mientras mayores sean sus elementos propios y serán, concomitantemente, menos propensas a entrar en conflicto, cuando tengan mayores elementos comunes.

Por la falta de elementos comunes entre los ordenamientos jurídicos nacionales es que los autores clásicos del siglo XIX, tachan al Derecho Internacional Privado como un derecho imperfecto, porque sus detractores aprecian más las dificultades para su aplicación internacional y porque no es dable al Estado Nacional extender su protección legal, mientras que los 
ordenamientos jurídicos nacionales si cuentan con todos esos elementos y con los órganos jurisdiccionales ante los cuales se puede reclamar su aplicación obligatoria y generalizada (Carrillo Salcedo, 1991).

En la eventual concurrencia de leyes nacionales, teóricamente con el mismo mérito para poder regir sobre una relación entre individuos o sobre un acto que han protagonizado individuos o que se éstos vean involucrados, esto es cuando esa relación o ese acto entre individuos tiene efectos jurídicos en más de un Estado, es precisamente cuando puede ocurrir un conflicto, una colisión, que haga necesaria una determinación previa para decidir que ordenamiento jurídico nacional es el que debe aplicarse.

El conflicto puede ocurrir sobre los ámbitos propios de las leyes nacionales que concurren y sobre las competencias derivadas de las leyes nacionales. Para superar el eventual conflicto de leyes o la posibilidad de colisión de leyes nacionales, es que se deben establecer reglas de aceptación generalizada, de parte de los dos o más Estados Nacionales en los cuales ordinariamente se aplican las leyes que concurren.

Por lo anterior, el Derecho Internacional debe tratar de la nacionalidad, sus fundamentos jurídicos y los sistemas para determinar nacionalidades, capítulo que tiene estrecha relación con los derechos de los extranjeros, para señalar las ocasiones en que más usualmente podrían ocurrir conflictos de leyes nacionales (Balestra, 1968).

Existen conflictos de leyes previsible es en materia de leyes civiles, lo que podría llamarse Derecho civil internacional, el que toca temas relacionados con la capacidad de los Estados Nacionales, a la forma de los actos, a las obligaciones, tanto las convencionales como las que nacen de la ley; a las cosas; al derecho de familia (matrimonio, divorcio, paternidad y filiación, tutela de menores e incapacidad) y de las sucesiones (Ortiz de la Torre, 1992). 
Un tercer gran capítulo tienen que ver con los conflictos de leyes de procedimiento civil, para abarcar la competencia, la forma de proceder, la presentación de pruebas, los trámites propios de las comisiones rogatorias y la ejecución de sentencias.

Otro ámbito ya mencionado en párrafos anteriores, de usuales conflictos es el relativo a las leyes comerciales, cuando se actos de comercio, de los comerciantes, de los mandatarios, de las sociedades comerciales, de las letras de cambio y otros títulos de crédito. Se incluyen, usualmente en capítulos separados, los temas relativos a la quiebra y suspensión de pagos.

El Derecho marítimo y el Derecho Penal merecieron ya consideraciones separadas, en el capítulo anterior (supra) relacionado con los ordenamientos jurídicos de alcances universal, porque en efecto fueron los que mayores oportunidades de conflicto de leyes provocaron en un pasado reciente y que, probablemente por ello, merecieron particular interés de la Comunidad Internacional organizada, que sucesivamente promovió convenciones multilaterales de alcance universal.

\section{LOS RELATIVISMOS EN LA APLICACIÓN DE PRINCIPIOS Y DE REGLAS EN LAS RELACIONES INTERNACIONALES CONTEMPORÁNEAS.}

En la ideal consolidación de la Comunidad Internacional, válida para alcanzar una mejor convivencia de los Estados, en sus relaciones entre ellos, cómo válida también para desarrollar las instituciones propias del Derecho Internacional Privado, para convenir en reglas generalizadas y si es posible universales para superar las colisiones de leyes nacionales, es importante considerar los relativismos con los que actualmente los Estados Nacionales tratan de aplican tanto los llamados principios y fundamentos del Derecho Internacional, como las reglas 
convencionales para el impulso de ciertas materias derivadas de la convivencia de los Estados y de los individuos.

Las acciones unilaterales de fuerza, por una parte, la obstaculización crítica para el avance de las negociaciones para alcanzar un nuevo orden económico internacional, por otra parte, o la negativa de ciertos Estados poderosos a comprometerse a establecer normas para el control de los cambios climáticos, nos podrían llevar a concluir en que la euforia por establecer una firme Comunidad Internacional, que existía en la segunda posguerra, ha dado paso a una actitud de los Estados para aplicar de manera relativa los principios fundamentales de la Comunidad Internacional; dicho con otras palabras, para que los Estados Nacionales pongan en práctica los principios y fundamentos que se recogieron en la Carta de las Naciones Unidas y que conforman toda otra aspiración, para consolidar nuevos órdenes, en materia mercantil, para el libre tránsito de las personas, para la protección del medio ambiente, etc.

Si bien un proceso generalizado de globalización, incluso a luz de las mencionadas nuevas actitudes de los Estados Nacionales, luce imparable, la consolidación de un poder hegemónico universal, se ha visto como una imposición de un sistema y de un modelo, que pretende tener preeminencia sobre otros. Si bien el resultado práctico de la imposición, si llegare a confirmarse, ayudaría a superar los eventuales conflictos de leyes nacionales, la ausencia de los aportes nacionales haría que la aplicación de las reglas fuere forzada y por ello de permanencia también relativa.

El proceso de globalización y el progreso de los medios e instrumentos de relación entre individuos, obligaría a que las mencionadas reglas no sólo que fueren estables sino que se caractericen por ser dúctiles, para ir perfeccionándose conforme la humanidad avance en el desarrollo de sus interrelaciones. La intención velada o abierta de los Estados para cumplir de manera relativa a sus intereses nacionales, podría dar lugar a la 
planificación de otros mecanismos alternativos, que implicarían una involución del avance que se supone que quería darse a la Comunidad Internacional.

La preeminencia de una postura nacional, aún cuando corresponda a la potencia hegemónica resultante del fin de la Guerra Fría, o los modelos alternativos anunciados anteriormente, pondrían en evidencia diferencias estructurales entre los derechos nacionales y el Derecho Internacional, Público y Privado. Estas diferencias están marcadas por los elementos comunes de los derechos nacionales y por la imposibilidad de encontrar todos ellos en el llamado "Derecho de Gentes", que se entendería como el recogido por la Carta de las Naciones Unidas y, aún cuando no sea estrictamente aplicable a la órbita del Derecho Internacional Privado, porque parecía el de común aceptación por parte de los Estados Nacionales.

En párrafos anteriores, quedo expresado, con respecto a esta falta de elementos comunes entre los ordenamientos jurídicos nacionales, que hay coincidencias entre autores clásicos del siglo XIX, para tachar al Derecho Internacional y Privado, como un derecho en formación, precisamente porque sus detractores de ese entonces y al parecer los nuevos detractores, al juzgar por sus posturas actuales, ponen énfasis en una serie de falencias para su aplicación universal, para su protección y debidas a las imposibilidades reales para ser obligatorio, antes que a los palpables avances hacia la universalización de las reglas.

Es acertado afirmar que los derechos soberanos nacionales si cuentan con todos esos elementos que se reclaman que faltan en el derecho internacional $y$ es cierto que los órganos jurisdiccionales nacionales, no tienen competencias, que no fueren convencionales, para reclamar por su aplicación obligatoria y generalizada, pero desde un punto de vista teórico, que esos autores clásicos y los nuevos detractores no quieren tocar, se supone que el derecho internacional es uno que está en formación 
porque nace de un propósito ideal que paulatinamente va creciendo, hasta alcanzar todos esos elementos reclamados.

En nuestros días, la validez de este paulatino crecimiento si se demuestra en ámbitos universales tan importantes como el relacionado con los derechos humanos, con la protección del medio ambiente y en varios campos especializados, como el del derecho del mar, pero precisamente por los propósitos de los Estados Nacionales que parece que quieren reivindicar sus competencia propias frente a las voluntariamente concedidas a la Comunidad Internacional, en ciertos otros campos, como el atinente a la seguridad internacional, a la migración, al derecho penal internacional, puede creerse que el Derecho Internacional Privado es uno que tarda en avanzar o que sigue mostrando extrema fragilidad.

En lo que atañe a la relatividad para el cumplimiento de los principios sostenedores de la Comunidad Internacional y de los compromisos adquiridos por los Estados Nacionales, en virtud a convenios internacionales, es ciertamente más grave para esa Comunidad la relatividad relacionada con la convivencia entre Estados, que la que tiene que ver con las relaciones internacionales de los individuos particulares; pero en el campo teórico del derecho no cabría hacer diferencias entre los cumplimientos relativos, los incumplimientos y las violaciones de los principios y de los compromisos, porque unos y otros responden a la voluntad de los Estados para adquirir obligaciones internacionales.

Lo dicho en el párrafo anterior se justifica en el devenir práctico de la vida de relación internacional, donde si deben anotarse más profundas y trascendentales repercusiones para la Comunidad Internacional por el empleo unilateral de la fuerza, por ejemplo, porque con ello se trocaron los términos de aplicación de los principios pilares al pretender plantear la existencia de un derecho a intervenir, en determinadas circunstancias y bajo condiciones preestablecidas por un Estado 
Nacional, lo que significa realmente dejar a un lado el derecho de protección de los Estados precisamente para no sufrir intervenciones de otros Estados.

El cumplimiento relativo, el incumplimiento o la violación de los compromisos para aplicar ciertas reglas convencionales, en casos de concurrencia de leyes de distintos Estados, traerá consecuencias negativas a particulares, especialmente, lo que podría ser menos grave para la Comunidad Internacional, sino se consideran los precedentes negativos para las comunidades nacionales y la involución en el desarrollo del Derecho Internacional Privado.

\section{LOS RELATIVISMOS Y LAS CONVENIENCIAS NACIONALES}

Lo ocurrido en el mundo al final del siglo pasado y lo que puede suponerse que seguirá ocurriendo por el cumplimiento relativo de principios de la Comunidad Internacional y de compromisos asumidos por los Estados Nacionales, en el ámbito internacional, puede permitir que se afirme que incluso el relativismo de los compromisos internacionales, en general, está directamente vinculado con el interés y la conveniencia que pudieren tener los Estados, tanto para cumplir como para obviar el cumplimiento cabal de dichos principios y reglas convencionales (Posso Serrano, 2007).

Aún en el supuesto de dar por válido el interés y la conveniencia de un particular Estado Nacional, sobre los intereses y conveniencias de una Comunidad Internacional que todavía no termina por definirse, es incuestionable que a los Estados que no puedan ejercer presiones ni tengan suficiente fuerza, les conviene más luchar por el cumplimiento cabal de principios y de reglas convencionales, que dejar abierta una cadena interminable de cumplimientos a medias, de incumplimientos y de violaciones flagrantes. 
El hacer depender la voluntad política de los Estados Nacionales de su real poder y de su fuerza, permitiría que se ponga en marcha una competencia de esos Estados para alcanzar los suficientes niveles de fuerza, para poder darse el lujo de cumplir a medias; para cumplir de manera relativa; para incumplir sus compromisos internacionales; e incluso, en agravamiento, para violar los principios y las reglas convencionales

Sin tratar de hacer afirmaciones infundadas, si parece que uno de los objetivos que buscan ciertos Estados Nacionales envueltos en procesos de integración, es el de mejorar su situación de presión y de influencia en los ámbitos internacionales, bajo la premisa de que en conjunto se logra mayor respeto. Si esa mayor influencia podría servir para justificar los relativismos en el cumplimiento de los compromisos internacionales, podría equivaler a sostener que la integración de esos Estados conduce a poder imponer, relativamente y en comparación con la influencia de potencias mayores, modelos y soluciones diseñadas para satisfacer sus particulares necesidades, no precisamente las necesidades de la Comunidad Internacional.

Una mayor elaboración de la premisa anterior, en un supuesto no consentido de buscar mayor influencia para imponerse en la Comunidad Internacional, puede permitir que se analicen los riesgos del relativismo de los principios y de las reglas convencionales bajo la luz de la conveniencia de los mismos para los Estados Nacionales y para sus individuos. Será posible entonces elucubrar sobre muy distintos enfoques, que los Estados Nacionales se hubieren planteado acerca de sus intereses como Estados y de las conveniencias de sus nacionales, porque a su vez, internamente, creerían que podría ser estratégico dejar sin avanzar las instituciones que la Comunidad Internacional planificó, para hacer prevalecer, en su lugar, sus propios modelos y sus soluciones, nacionales o regionales, no universales.

Frente a esta posibilidad, que incluso únicamente sirve como punto de análisis académico, si cabe que se analice también 
la contrapartida de los Estados Nacionales menores, que no cuenten con un confiable proceso de integración, y que teman porque el relativismo de los principios y de las reglas convencionales y la preeminencia de las conveniencias nacionales de los Estados poderosos, para aplicar de manera relativa o para incumplir flagrantemente con sus obligaciones convencionales, relativas a principios y a reglas, haría de hecho mucho más frágil la integridad de los Estados menores y los intereses y conveniencias de sus nacionales.

Esa contrapartida de los Estados menores podría tomar la forma de una reacción ante los intentos, reales o exagerados, de los Estados poderosos de los medianos o podría originar una corriente de análisis académico y de coordinación de posiciones prácticas, para proponer modelos y soluciones que resulten convenientes para la Comunidad Internacional y, al menos, aceptables para los Estados poderosos y medianos, que tendrían que volver a cifrar sus esperanzas en la estabilidad y la durabilidad de los principios y de las reglas de relación internacional, entre Estados y entre particulares.

Cualquiera que fueren las razones, ocultas o abiertas, certeras o exageradas, es evidente que existen los relativismos y que pesan las conveniencias y que es fundado el temor de que cualquier Estado o sus nacionales pueden sufrir los atropellos y los abusos del "derecho privilegiado" de otros Estados o de los particulares de esos Estados poderosos.

Esta convicción lleva a la certeza de que los principios del Derecho Internacional Privado serán exigibles ahora de otra manera que a mediados del siglo XIX, cuando se perfilaban las instituciones propias del Derecho Internacional Privado o a mediados del siglo pasado, cuando se pusieron las bases para la nueva Comunidad Internacional que debía nacer de los despropósitos de la II Guerra Mundial.

Aparte de lo expresado, es también evidente que las conveniencias nacionales para respetar o desconocer principios y 
reglas convencionales resultan, en la práctica, múltiples y que por ser tales, convendría a todos los Estados, grandes, medianos y pequeños, y a todos los particulares de esos Estados, partir de modelos y de soluciones que se previeron como útiles para desarrollar toda la Comunidad Internacional, no sólo un sector de la misma.

En ese intento habría que poner especial atención para evitar que los intereses de los particulares, proyectados a nivel internacional, puedan ser vistos desde muchos ángulos y puedan tener asidero en innumerables facetas, puesto que se justifican precisamente en los relativismos de los principios y de las reglas convencionales y esos relativismos, descansan en las interpretaciones de los Estados Nacionales que dicen responder a las conveniencias propias de sus nacionales; esto es que los Estados Nacionales suelen justificar sus posturas y pretensiones en la defensa de los intereses de los individuos.

Habría que tratar de desechar la conclusión de que en realidad se trata de un círculo vicioso, que comienza por la anunciada necesidad de que los Estados Nacionales, defiendan los intereses y las conveniencias de sus individuos, y que pasa por la exposición de planteamientos orientados bajo sus particulares ópticas, para sostener, con el propósito de cerrar el círculo, otra vez la afirmación de que los relativismos se deducen de las interpretaciones que tuvieron que hacerse por la aplicación relativa de principios y de reglas convencionales.

$\mathrm{Si}$ es válida, en cambio, la conclusión de que las conveniencias de los particulares fueron tomadas en cuenta por los Estados Nacionales que usualmente responden a coyunturas que esos Estados enfrentan, con lo que se hace aún más relativo un principio o una regla convencional que en el siglo XIX y a mediados del siglo XX, se creyó que podrían ser fundamentales para la edificación de Comunidad Internacional, la que daría un marco adecuado para superar los conflictos de leyes, por una parte, y para conseguir una mejor convivencia entre los Estados. 


\section{REPERCUSIONES PRÁCTICAS DE LOS RELATIVISMOS}

Ciertamente que hace muy pocos años, en la posguerra de la II conflagración mundial, la traumática experiencia vivida por la humanidad, provocó que líderes y académicos se muestren convencidos de que las sociedades se enfilaba a nuevos destinos de justicia, de equidad, igualdad y solidaridad. Muchos coincidían en afirmar que se había demostrado la necesidad práctica para los Estados de ir cediendo a la Comunidad Internacional las facultades soberanas nacionales, en aras de un orden coherente y firme, el mismo que se suponía que garantizaría el irrestricto ejercicio de derechos y libertades fundamentales, por parte de todos los componentes de esa Comunidad. Pocos dudaban acerca de que todos esos componentes de la nueva Comunidad Internacional, que surgía del fin de la guerra, no fueran sujetos reales del Derecho de Gentes.

En esos primeros años de la posguerra, se tenía fundadas esperanzas en el desarrollo de la institucionalidad del Derecho Internacional Privado, según la concepción que se puso en boga, parecía que el desarrollo obedecería a una voluntad política existente y al evidente fortalecimiento de de la Comunidad Internacional, que a todos parecía estar dispuesta a proponer modelos y reglas de soluciones para los conflictos de leyes, que por el avance de los compromisos entre los Estados, cada día serían menos frecuentes.

Al partir de este auspicioso panorama a la realidad actual, podría notarse que habría una intención de los Estados Nacionales a volver a sus posiciones del siglo XIX, para que esas posiciones respondan, de mejor manera según la justificación, a los intereses y conveniencias de sus nacionales. Los afanes explicitados en los primeros años de la posguerra no habrían sido dejados a un lado, oficialmente, pero el nuevo enfoque significa que no es necesaria la consolidación de los principios y de las reglas convencionales, 
porque los nuevos órdenes que se diseñaron no descansan necesariamente en el fortalecimiento de la Comunidad Internacional, sino en el desarrollo de las facultades implícitas de algunos privilegiados Estados Nacionales, facultades éstas a las que se supone renunciaron, precisamente cuando suscribieron la Carta de las Naciones Unidas, vista como el nuevo origen de la Comunidad Internacional

En el análisis que podría hacerse, aún cuando fuera sólo con afán académico, podría arribarse a una primera conclusión general sobre la necesidad real de consolidar la Comunidad Internacional, para impulsar la institucionalidad del Derecho de Gentes (con las reservas admitidas, tal Derecho de Gentes podría ser equivalente al Derecho Internacional Privado, en los ámbitos anotados) y por ende reaccionar en contra de los Estados Nacionales que propugnan el mayor valor de sus facultades implícitas recobradas (la oposición a adherir al Protocolo de Kioto, la negativa a extender para los soldados estadounidenses el Estatuto de Roma sobre justicia penal internacional, las nuevas restricciones para el tránsito de personas).

Para explicar mejor el punto anterior, cabe que se recalque que en la reacción que se vislumbra, para el real fortalecimiento de las instituciones del Derecho Internacional Privado, ya no cabría el recurrir a reclamar la igualdad jurídica de todos los Estados Nacionales, sino aceptar que algunos de ellos, los Estados poderosos y los que quieren encontrar poder suficiente en sus exitosos procesos de integración, si están abriendo el camino hacia el fortalecimiento de facultades nacionales mayores. La respuesta que se espera de Estados menores, en consecuencia, no podría, por estrategia, emular a los Estados poderosos en la búsqueda y consecución de mayores podres para influir, sino propender al desarrollo real de la Comunidad Internacional, como garantía de estabilidad y de aplicación universal de las reglas convencionales. 
Incluso cabe esperarse que los pequeños Estados que, dejando a un lado falsos caudillismos regionales, logren promover un auténtico proceso de integración no entren en una carrera de competencia sobre mayores influencias para imponer sus modelos $\mathrm{y}$ sus soluciones, sino que retomen los principios y las reglas convencionales que tienen mayores proyecciones de aplicación generalizada y universal (Verdross, 2000).

\section{El VAlOR RELATIVO DE LAS CONTRIBUCIONES NACIONALES}

La posición lógica que tendrían que asumir los Estados, para que fuere más trascedente si tendría que considerar que en todo lo que tiene que ver con la determinación de acciones específicas, una mayor o menor participación en la toma de decisiones de la Comunidad Internacional, dependerá de los grados reales de influencia de los Estados miembros.

Frente a esa realidad, las posturas de Estados, individualmente considerados, para que pesen en el concierto internacional tendrán que verse respaldadas por el peso específico del Estado Nacional, que de ser escaso, habría que sumarlo a los pesos específicos de los Estados Nacionales que comparten la posición del primero.

El proceso que tienen que pasar los Estados Nacionales menores para conseguir los respaldos de sus pares, es bastante intrincado, pues suele pasar de una evolución desde la tolerancia de los otros Estados a su convicción de que la postura nacional específica, resulta también conveniente para los intereses de sus nacionales.

Precisamente por esta necesidad de someter las posturas nacionales a un proceso de aceptación y de apoyo ulterior, es que deben rodearse a las posturas nacionales de suficientes elementos de convicción y de atracción. La fundamentación de las posturas 
en principios, es una buena estrategia por la aceptación previa de los Estados de la validez de esos principios.

Por una parte, entonces, la relatividad de los aportes nacionales si está en la coherencia de las posturas con los principios; en la solidez de los enfoques; y en el alcance real de los modelos y soluciones. Pero otra consideración fundamental está en que los Estados Nacionales tienen que reconocer, aún cuando fuera a regañadientes, que en la Comunidad Internacional operan las influencias mayores, medianas y menores y que esas influencias, en muchas oportunidades, pesan mucho más, en la toma de decisiones, que los valores intrínsecos de las propuestas nacionales.

Una final consideración tiene que ver con la situación, el prestigio y la trayectoria de los otros Estados Nacionales que hubieran sido convencidos por el Estado que propone un determinado modelo $\mathrm{y}$ unas específicas soluciones. Las asociaciones tácticas deben cuidar no únicamente la coherencia entre los sistemas jurídicos de los Estados asociados estratégicamente, para apoyar una postura, sino de la capacidad de influencia en la Comunidad Internacional de cada uno de ellos. Una buena propuesta, promovida por Estados Nacionales desprestigiados, por ejemplo, tiene pocas posibilidades de éxito para consolidarse dentro de la Comunidad Internacional.

\section{LAS CONTRIBUCIONES DE LOS ESTADOS Y ALIANZAS MENORES}

Me parece que este punto cabe que insista en una opinión para vincular la aplicación, de manera relativa y según las conveniencias y los intereses de los nacionales de un Estado de los principios y de las reglas del Derecho Internacional Privado con las esperadas posiciones de la potencia hegemónica y de los Estados mayores, puesto que la que la potencia hegemónica no quisiera permitir resquebrajamientos dentro del bloque que lidera Ius Humani, v. 2 (2010/11), p. 100 
y los Estados mayores querrán formar otro bloque que se oponga al liderado por la potencia hegemónica.

Suele ocurrir que los Estados menores e incluso las alianzas que estos Estados pueden hacer, intenten acudir en apoyo de las posturas de la potencia mayor o, en caso de querer abrir un frente de oposición a la misma, se acerquen a las posturas exhibidas por los Estados mayores envueltos en un proceso exitoso de integración.

Hay por otra parte, algunas coincidencias en la defensa de ciertos "valores" culturales (entre ellos los atinentes al campo jurídico) por parte de Estados mayores y menores. En América, por ejemplo, la defensa de los valores de la cultura occidental es compartida por la potencia hegemónica, por los Estados mayores del continente y por los Estados menores.

Esta más o menos coincidencia americana, referida al continente entero, no se extiende necesariamente a los sistemas jurídicos imperantes en el norte del continente y en el sur, pero históricamente si se han dados intentos de crear un derecho internacional americano, por ejemplo, con los aportes del derecho consuetudinario anglo-sajón y el derecho racional, latinoamericano.

En materia de estos aportes y de sus valores, tendría que operar también otro relativismo, esté último encadenado a las posibilidades reales de las entidades menores para influir en la potencia hegemónica y en el bloque creado por los Estados mayores, y a las posibilidades que existan para que la potencia hegemónica y los Estados mayores reemplacen la eventual contribución de los Estados menores, con otra u otras aportadas por distintos Estados, individualmente considerados, o por alianzas de ellos, mejor dispuestas a sumarse a los bloques, sea el liderado por la potencia hegemónica o el conformado por los Estados mayores que rivalizan con ella.

En este juego de preferencias por unos aportes de Estados menores o por otros, queda implícita una especie de amenaza de 
que el Estado menor o la alianza de Estados menores, que se nieguen a contribuir o que no estén capacitados para hacerlo, queden aislados. El ostracismo de un Estado menor es más grave en el campo de las relaciones internacionales. En el que atañe al Derecho Internacional Privado el aislamiento podría significar la imposición de una solución ajena al Estado menor, que considere únicamente la conveniencia y los intereses de otros Estados, no las propias.

Muchos sostenedores de la tesis de que es imposible frenar la globalización, suelen elaborar sus teorías, muy similares, en torno a este posible aislamiento de Estados renuentes al proceso. Quizás con la explicación de los relativismos se podría afianzar, de cierta manera, la descripción del riesgo cierto del aislamiento, si se aprecia éste como la consecuencia de no ofrecer una contribución relativamente apreciable; cuando se trata de negarla, para conseguir un eventual mejor tratamiento; en los casos en que la contribución fuere fácilmente reemplazable; o cuando aparezca un Estado que se manifiesta abiertamente antagónico.

En la tarea de conceder primero internamente el valor real que pueden tener las contribuciones nacionales, no caben las apreciaciones elementales ni las repeticiones de creencias populares, por más extendidas que éstas sean, puesto que si bien existen los relativismos y las conveniencias de los Estados Nacionales, para la valoración de las contribuciones de otros Estados, se ha puesto ya en marcha una escala absolutamente pragmática, que toma en consideración razones de diversas índoles, del Estado Nacional, y las potencialidades de los modelos y de las soluciones propuestas.

Se ha tornado tan objetiva esta apreciación que La Comunidad Internacional y los Estados influyentes aceptan, de buena gana, los aportes de recientes enemigos y la expresión de antiguas amistades sólo si sirven en el grado y en el nivel de la influencia real que se espera de los aportes del reciente enemigo o del antiguo amigo. Se suelen ahora separar, con severidad, las 
esferas, los grados y los niveles de esas influencias en las contribuciones de Estados nacionales.

\section{El desarrollo del Derecho Comunitario}

El panorama descrito no debería implicar un fatalismo para los Estados menores, para sostener que ellos simplemente deberían dejarse llevar por la corriente y terminar acoger modelos y soluciones ajenas o por saber que, en un momento determinado, van a ser ignorados por el escaso valor de sus eventuales contribuciones, peor por su postura antagónica

$\mathrm{Si}$ se siguiera la línea del fatalismo, únicamente cabría luchar para que la asimilación ocurra "en las mejores posiciones posibles" para el Estado menor. En otras palabras, si se llegare a reconocer que sólo cabe la posibilidad de buscar la menos traumática manera para ser absorbido o para dejar a salvo lo más importante de las conveniencias e intereses de sus nacionales, el Estado menor tendrá que analizar también si las alianzas estratégicas que ha intentado y los procesos de integración en los que ha intervenido, han tenido resultados. Si se arriba a la conclusión de que tales intentos, para desarrollar algún proceso que haga contrapeso a la potencia hegemónica a los Estados mayores, condujeron a rotundos fracasos, por una serie interminable de incumplimientos o incluso, cínicamente, porque algunos Estados de la región se imaginaron más cómodos formando parte, aún cuando fuere insignificante, de la potencia mayor, el Estado menor tendría que simplemente resignarse a la absorción o dejar a un lado los antagonismos deliberados, como mal menor para evitar el aislamiento o a la anulación de sus posturas particulares.

Ese panorama es el que da cabida a la edificación de los derechos comunitarios, aún cuando fuere como pasos intermedios para llegar a un único derecho mundial, que se impusiere con el nuevo orden. En esa edificación de los derechos comunitarios se 
podría volcar los afanes e impulsos que pudieron haberse frustrado al contemplar que se abandonaba, o se dejaba a un lado, el propósito anterior de consolidar la Comunidad Internacional.

Los derechos comunitarios, entonces, serían las nuevas instituciones que tendrían que desarrollarse para buscar, por esos medios, una eventual consolidación de una nueva Comunidad Internacional, que se organizaría bajo otros parámetros para dar cabida a los "bloques" que la globalización mundial prevé, a los Estados mayores y a los Estados menores.

Existen muy pocas discrepancias cuando se analiza el proceso imparable de la globalización mundial, por ello, la presencia de bloques y megabloques es prácticamente incuestionable, lo que no quiere decir que haya concordancia en imaginar las razones fundamentales, los impulsos y los motores para la edificación de los bloques y el número de ellos, en el ámbito mundial.

Incluso, en cuanto a lo que este documento esboza, es muy probable que los análisis que he hecho sean pesimistas, aún cuando tuve la intención de ser simplemente premonitorio, y siendo así, para que las conclusiones que he sacado no obedezcan a un cálculo certero de las coyunturas futuras, de lo que realmente puede pasar, máxime si hay también una tendencia universal para desarrollar esos derechos comunitarios, conceptuados como conjuntos de normas que rigen las acciones y los compromisos de los nacionales de varios países, bajo esquemas distintos a los de las leyes de los Estados Nacionales, aún cuando las normas comunitarias no pueden ser extrañas a los ordenamientos jurídicos nacionales, que fueron los que las inspiraron y alimentaron.

Concebido de esta forma el derecho comunitario no se puede negar que está en un franco proceso de desarrollo, dentro de varios esquemas de integración y de concertación política. El progreso real de cada uno de los procesos de integración o de concertación depende, por supuesto, del éxito alcanzado por las Partes que quieren integrarse o coordinar sus acciones $y$ 
determinaciones políticas, pero aún en los casos de procesos que marchan con dificultad o incluso en los casos en que los procesos se han visto frustrados, los intentos que se hicieron para crear normas comunitarias son válidos, no únicamente desde un punto de vista teórico, sino también porque pueden ser utilizados como elementos para revivir o reactivar los intentos para crear modelos y proponer soluciones convencionales; y para reactualizar procesos de integración y mecanismos de concertación, frustrados antes, en mayor o en menor medida.

En la consideración ideal del derecho comunitario, que aun cuando sea teóricamente haría innecesarios, en sus últimas etapas de consolidación al Derecho Internacional tanto Público como Privado, hasta lograr constituir un solo orden universal, si podrían darse conflictos de leyes entre los distintos derechos comunitarios. En esa probable situación, siguiendo el planteamiento del Derecho Internacional Privado, habría que buscar la adopción de modelos y de reglas, para las distintas entidades regidas por un particular derecho comunitario, acuerden poner en marcha para superar las colisiones.

Por cierto que los derechos comunitarios del futuro próximo se fundamentarían en instituciones menos distintas de las que dieron lugar al conflicto de leyes propio del Derecho Internacional Privado. Dicho de otra forma, las instituciones que se crearían en los distintos derechos comunitarios, tendrían mayores elementos comunes, porque el mismo proceso imparable de globalización hace que la humanidad se oriente a metas comunes y porque la Comunidad Internacional tendrá que hacer valer, como ejemplos para ser imitados en el campo propio del derecho comunitario, todos los procesos exitosos que auspició, para citar como ejemplo ilustrador, el relacionado con los derechos humanos, el derecho internacional del mar, la protección del medio ambiente, etc.

En consecuencia, el nuevo conflicto entre derechos comunitarios, muy posiblemente no requerirá de la adopción de intrincados códigos para manejar las situaciones sometidas a 
ordenamientos jurídicos diversos, precisamente porque, al parecer, no serán tan diversos. De cualquier manera tendrán que establecerse procedimientos para la determinación de competencias y entonces cabría abrir espacios para intercalar los fundamentos de sistemas jurídicos que un grupo de Estados Nacionales quisieran preservar.

Bajo razonamientos similares a los usados para medir la importancia de las contribuciones nacionales para la edificación de los bloques, la validez de las instituciones que los Estados que respondan a un sistema jurídico, quieran promover, no podrían sólo descansar en la importancia que cada bloque conceda a sus instituciones de derecho comunitario, sino mayormente a la aplicabilidad universal y generalizada de las instituciones, especialmente desde el punto de vista que tales instituciones deben ser vehículos de unión o deben permitir la tolerancia, al menos, de las normas más amplias del derecho comunitario que corresponda a los de Estados promover y en relación con las normas de otros derechos comunitarios, en aparente o evidente colisión o en eventual conflicto.

Las llamadas "corrientes jurídicas" actuales, en el mundo contemporáneo, si bien, por una parte, facilitan la uniformidad de disposiciones nacionales, dentro de cada corriente, y hacen menos complicado el avance hasta una unificación ideal universal, al mismo tiempo tornan sumamente complicada la supervivencia, dentro de un conjunto de normas comunitarias, de instituciones demasiado locales y estrictamente nacionales. Las corrientes jurídicas sirven, entonces, también como elementos catalizadores de una posición o tendencia que caracterice al bloque $\mathrm{y}$ al purificar esa tendencia, debieron haber sido desechadas las posturas estrictamente nacionales o demasiado locales.

Una situación que podría plantearse, como ejemplarizadora para explicar la última posibilidad, estará en la enorme dificultad de que dentro de las normas comunitarias europeas se encuentre acogida para instituciones de alguna región específica de uno de 
los Estados de la Unión, cuyas raíces jurídicas se remonten a fuentes extrañas al común Derecho Romano, podría servir para explicar más el ejemplo alguna institución turca basada en Derecho islámico. Asimismo, el mantener, en un panorama futuro, la aplicación discriminada de las llamadas "leyes propias", por parte de comunidades indígenas americanas, podría resultar un propósito demasiado remoto para hacerlo realidad, puesto que tales leyes ya no serían sólo inconsistentes dentro del entorno doméstico, el del país que forman parte esas comunidades, sino además serían normas incoherentes con el ordenamiento comunitario que se pretende edificar.

Para volver al tema de un derecho comunitario americano, cabe recordarse la génesis del llamado Derecho Internacional Americano, para poder visualizar los contornos que podría tener una eventual conformación del primero. En efecto, es lógico pensar que si el derecho americano se nutrió de dos fuentes diversas, y en varias ocasiones contrarias, una que venía de América Latina, con instituciones propias basadas en el desarrollo del pensamiento racional, instituciones éstas que buscaron una concordancia práctica con las instituciones del derecho estadounidense, a su vez desarrolladas del derecho consuetudinario anglo-sajón, se puede esperar que para la construcción de un eventual derecho comunitario americano, se busquen concordancias entre las instituciones jurídicas del norte del continente, incluidas las del Canadá, y las instituciones del centro y sur de América, algunas de esas instituciones predominantemente cartesianas, las propias de Sudamérica, pero otras del Caribe, de origen anglo-sajón.

Salvo la subsistencia en el ámbito americano, de instituciones muy particulares, como el derecho de asilo que siempre fue estrictamente latinoamericano, puede decirse que dentro del Sistema Interamericano fue adquiriendo mayor importancia el aporte jurídico de los Estados Unidos, especialmente si recordamos la imposición de principios relativos 
a la protección y difusión de instituciones de democracia representativa, por ejemplo, o las normas de seguridad colectiva e incluso las mismas políticas de cooperación intercontinental.

Las Partes latinas de América fueron quizás paulatinamente adoptando como propias instituciones de fuentes jurídicas del norte, por lo que el Sistema Interamericano, considerado en su globalidad, es más parecido, jurídicamente, a las instituciones del derecho anglo-sajón desarrolladas por los Estados Unidos y por el Canadá.

Si sumamos a la tendencia globalizadora mundial, que envuelve también a las instituciones jurídicas, la experiencia vivida dentro del Sistema Interamericano, podríamos esperar una preponderancia de las instituciones del norte de América, máxime si los relativismos de los principios y las conveniencias nacionales hubieran hecho que se deje a un lado la consolidación de la Comunidad Internacional, como requisito fundamental para el progreso del Derecho Internacional Privado.

Es sólo probable, pero no del todo desechable, que en la construcción del nuevo Derecho Comunitario, no haya mayor cabida para las instituciones que provienen de grupos extremadamente nacionalistas, peor de corrientes que se quieran imponer sobre bases no totalmente compartidas de líderes históricos no sólo anteriores a los procesos modernos de integración, sino incluso anteriores a las identidades nacionales.

En definitiva, los papeles reservados para las entidades nacionales, para el desarrollo de los derechos comunitarios, tendrán que ser unos que partan de la necesaria coordinación con los elementos políticos, económicos, militares y de todos los otros órdenes, que tienen que tomarse en cuenta para la consolidación del bloque respectivo e incluso para ofrecer la contribución que los Estados mayores y menores estén dispuestos y en capacidad de hacer, bajo los requerimientos de la reforzada Comunidad Internacional. 


\section{ELEMENTOS COMUNES EN LOS DERECHOS COMUNITARIOS}

Si se acepta como posible que los conflictos de leyes entre derechos comunitarios del futuro serán mucho más fáciles de superar debido a la cantidad de elementos comunes que los distintos derechos comunitarios pudieron haber desarrollado; si se toman en cuenta los modelos internacionales sobre muchas materias; los efectos de la globalización; las respuestas usuales a las corrientes de opinión; e inclusive los esfuerzos incuestionables de los países de construir normas jurídicas que respondan a los retos similares de un mundo cada vez más interdependiente e interrelacionado, habría que tratar de hacer un esfuerzo de identificación de instituciones de derecho comunitario, que hoy día ya se ven perfiladas en similares principios y fundamentos.

Es cierto que resulta complicado el realizar análisis comparativos de los distintos derechos comunitarios que actualmente podemos contar, puesto que inclusive el nombre mismo de "comunitario" parece que es reclamado como propio de la Comunidad Europea que, incuestionablemente, ha desarrollado normas jurídicas válidas para toda la Unión Europea, desarrollo que no es comparable con el logrado por otros procesos, especialmente hago referencia al derecho comunitario del Mercosur, dicho sea de paso también más logrado que el derecho comunitario de la Comunidad Andina, que es también digno de considerarse en un eventual análisis comparativo, aun cuando la misma CAN se encuentre actualmente sometida a una aparente inacción e incluso a un desmembramiento.

Hechas todas las salvedades que caben formularse por estas consideraciones relacionadas con los procesos legislativos comunitarios y con los sistemas aplicados para poner en marcha real a las normas de cada proceso actual de integración, si puede resultar coherente un intento de encontrar elementos comunes, entre los distintos ordenamientos jurídicos comunitarios, en el 
entendido de que no obstante su diferente desarrollo, que es siempre menester tener presente, tanto los derechos comunitarios más evolucionados, como los que estén en etapas iniciales, todos éstos, deberán seguir avanzando en sus procesos de consolidación y vigencia, en sus respectivos ámbitos y competencias.

En esa línea de apreciación de la vigencia, el ámbito y las competencias de los derechos comunitarios, debe considerarse que en las etapas actuales, incluso de los más desarrollados, los avatares de la integración a la que responden unos y otros, pueden ocasionar avances no previstos y retrocesos no calculados, por una vinculación mucho más profunda que en los derechos nacionales, con los factores políticos.

En este sentido relativo a la vinculación entre lo jurídico y lo político se inscribe no únicamente el avance real de las acciones y estrategias de las políticas comunitarias de sustento de las normas jurídicas, sino también los eventuales cambios en la voluntad política de los Estados miembros de una comunidad específica, cambios éstos que pueden ocasionar la inaplicabilidad práctica de alguna o algunas normas comunitarias.

Ciertamente que la proyección de una norma comunitaria europea, por ejemplo, tienen mayores garantías de mantenimiento, que una norma comunitaria andina, para seguir con el ejemplo, pero tanto la norma comunitaria de la UE, como la de la CAN, pueden llegar a enfrentar eventuales nuevas consideraciones políticas, relacionadas con esta mencionada "utilidad práctica", si el ámbito de referencia pierde sentido o si es menester modificar metas y estrategias.

Atentas todas estas consideraciones, pienso que podría ser útil para estudiantes y analistas plantearse ciertas características del derecho comunitario, fuere de la UE, como del Mercosur o de la CAN e inclusive el que eventualmente surja del novísimo mecanismo de Unasur, siempre con las salvedades anotadas acerca de la vinculación del desarrollo de las normas comunitarias con el proceso de integración respectivo y teniendo muy presente 
que ese mayor o menor desarrollo de las normas comunitarias de un determinado proceso de integración, por el avance del mismo sería muy difícil desecharlas, si por los cambios de actitud de los gobernantes ese determinado proceso de integración entra en crisis (Borchard, 1999).

Esta última referencia, que no pretendo que implique una apreciación crítica de mi parte, obedece por ejemplo a los obstáculos que tendrá que superar la Unión Europea por la crisis de la "eurozona" y por una eventual desarticulación de la CAN, por ejemplo, por el riesgo de quedarse al final conformada por dos de los antiguos 5 Estados Miembros. Las normas comunitarias europeas, relacionadas con el euro, y muchas normas andinas de comercio se seguirán aplicando aún en el peor escenario imaginable sobre el destino de uno y otro proceso de integración.

\section{ORÍGENES DEL DERECHO COMUNITARIO}

Fuere el derecho comunitario europeo, el latinoamericano o el del cualquier otra latitud mundial, los orígenes del derecho comunitario están en los convenios, suscritos entre sujetos de Derecho Internacional, convenidos en lo que quedan establecidas con diáfana claridad los derechos y las obligaciones de los Estados partes.

Podrán haber diferencias en los mecanismos previstos para poner en vigencia real a esos derechos y obligaciones, dentro de un marco general relativo a un proceso de integración determinado y por ello ciertos derechos y obligaciones previstos en los convenios multilaterales, en ocasiones serán meramente formales, mientras que en otras alcanzarán niveles reales de exigibilidad y hasta repercusiones por incumplimientos, por haberse adecuadamente previsto medidas para hacer valer la responsabilidad de los Estados Partes que asumieron el compromiso. 
En todo caso, no puede hablarse de un convenio constitutivo del proceso, son por lo general algunos convenios, que van alcanzando metas sucesivas, conforme se desarrolle el compromiso original. La pluralidad de convenios, una característica esencial del derecho comunitario, va acompañada de la sucesión de pasos o etapas, los primeros pasos son los previstos en los convenios originales, mientras que los pasos sucesivos constan en los convenios de enmiendas.

Tanto los convenios originales como los de enmienda, tienen una génesis usual, que parte de una iniciativa, que se traduce en una conferencia intergubernamental, en la que se negocian los términos de los convenios, y que de esa conferencia surge en el documento el compromiso formal.

Por ende, el compromiso formal de los Estados Partes debe considerar: obligaciones vinculantes; y los mecanismos para la toma de decisiones y resoluciones, sabiéndose que por la competencia dada a la comunidad por los Estados, muchas de esas decisiones y resoluciones (no todas, por supuesto) serán también de cumplimiento obligatorio.

\section{BASES DE LOS DERECHOS COMUNITARIOS.}

Las normas comunitarias obedecen, en consecuencia, a los compromisos formales asumidos por los Estados partes, cuando perfeccionan los convenios fueren originales o de enmienda, y las bases fundamentales de las normas están en el reconocimiento común y de cada Estado parte del valor y de la vigencia de la norma comunitaria.

En ocasiones, este reconocimiento de la validez y vigencia de las normas comunitarias puede estar explícitamente recogido por las Constituciones políticas de los Estados miembros. En otras ocasiones, el ordenamiento jurídico común de los Estados concede a las normas comunitarias el valor que emana de los convenios suscritos, sin que no sea necesario ese reconocimiento explícito 
constitucional, porque es suficiente el reconocimiento genérico a todas las normas que nacen de convenios.

Internamente, cada norma comunitaria comparte los principios generales de derecho, de la jurisprudencia y de la costumbre, como fuentes usuales, pero especialmente $\mathrm{n}$ lo que tienen que ver con jurisprudencia y costumbre podrían requerirse de estas la validez de la competencia dada por los Estados miembros a la comunidad, no es, por ello, toda jurisprudencia y toda costumbre válidas como fuentes de derecho comunitario, sino la jurisprudencia propias de las normas comunitarias, no las de los sistemas jurídicos nacionales, y las costumbres comúnmente aceptadas como válidas.

\section{Características del derecho COMUNitARio}

El derecho comunitario refleja una realidad que descansa en el reconocimiento explícito o genérico de una identidad comunitaria, que por esencia no es la suma de las identidades nacionales de los Estados miembros de la comunidad, sino una identidad comunitaria propia: la europea, la andina, la sudamericana, por ejemplo. La identidad comunitaria no suprime a las identidades nacionales, no por ser andina se pierde la identidad ecuatoriana, pero la dimensión de la identidad comunitaria si va más allá de lo meramente nacional, alcanza lo regional, que por serlo tienen otros elementos de cohesión.

$\mathrm{Si}$ esos elementos de cohesión comunitaria son distintos a los elementos propios de la cohesión nacional, los alcances de las normas comunitarias prevén una cooperación reforzada, que también va más allá de la solidaridad nacional, la misma que se vincula con las propuestas y las necesidades sociales de los Estados nacionales.

La cooperación reforzada, vista como una característica definitoria del derecho comunitario, no se establece únicamente en el tácito pacto social de un Estado nacional, sino que consta 
explícitamente determinado en un convenio internacional suscrito por los Estados miembros y obedece a una previamente definida conveniencia nacional, la que dio origen al compromiso plasmado en los acuerdos.

La determinación de lo que puede o no resultar conveniente para los intereses de los Estados miembros, se supone que debió ser una de las razones principales para que tal Estado, soberanamente, decida sumarse al proceso forjador de la comunidad.

En consecuencia con lo anterior, la conveniencia para el Estado nacional persiste, aún en situaciones de crisis; de manera tal que todas las Partes involucradas en el proceso, por conveniencia, están obligadas a reforzar sus esfuerzos y su cometimiento, precisamente en las épocas de crisis, porque una específica debilidad de la comunidad afecta sobremanera a las Partes. El reforzamiento de los Estados nacionales para acudir a solucionar una debilidad aparecida o agravada dentro de la comunidad, es lo que conforma la llamada cooperación reforzada, que no sólo obedece a una buena voluntad de los Estados partes, individualmente considerados, sino a una conveniencia para superar o para evitar el daño que la debilidad identificada podría provocar.

La cohesión comunitaria, que me he permitido diferencias de las cohesiones nacionales y el compartir obligado de fortalezas y debilidades, justifica otra característica fundamental del derecho comunitario, la transparencia, que debe primar en los trámites y procesos de formación, promulgación y puesta en marcha de las normas comunitarias.

A nivel nacional algunos regímenes autoritarios y absorbentes podrían eludir o restar importancia al derecho a la información sobre las génesis y los procesos legislativos, pero esa posibilidad resulta imposible de ponerla en marcha para controlar los órganos y los mecanismos legislativos comunitarios, porque los controles de los mismos deben ser superlativos, no únicamente 
porque todos los miembros de la comunidad ejercen la supervigilancia de las acciones y los mecanismos derivados de las normas comunitarias, sino también debido a que la responsabilidad de cada Estado miembro corre pareja con la responsabilidad de las otras Partes, dentro de un proceso que por esencia es entre "pares", porque no se trata de rediciones de superados imperialismos o de procesos de absorción política de entidades nacionales de potencialidades superiores.

Todos las anteriores características del derecho comunitario se amalgaman en una unidad que parte de los fundamentos para exigir una consecuencia directa de la norma con la materia regulada por la misma; de manera tal que exista la llamada eficacia directa, concebida ésta como la coherencia entre las exigencias planteadas para calificar a una norma como "comunitaria", en todo lo que tiene que ver con principios, y los efectos de la misma sobre las instituciones y los particulares, para poner pautas de conducta universalmente vigentes, en toda la comunidad, y universalmente exigibles, por las personas de una $\mathrm{u}$ otra manera involucradas en las acciones dispuestas por las normas y bajo garantías derivadas de los compromisos nacionales.

Los alcances de las normas comunitarias están determinadas con total precisión en los convenios, que son asimismo los marcos institucionales y los orígenes de los procedimientos previstos, dentro de un equilibrio entre las composiciones y las funciones de los órganos comunitarios, previstos asimismo en los tratados originales o de enmienda.

Este equilibrio, no sólo es una garantía adicional para la transparencia, de la que me ocupé en párrafos anteriores, sino que confirma el previo establecimiento de objetivos comunes comunitarios, unos determinados en los acuerdos fundacionales, otros en los acuerdos de enmienda y algunos provenientes de los órganos políticos de planificación de políticas comunitarias, que son adoptadas con el respaldo también político de los Estados miembros. 
Los objetivos comunes comunitarios son el alimento del proceso de integración, que es una línea de conducta que todos los Estados miembros deben asumir, con las únicas salvedades que se consideran en torno a las potencialidades nacionales, las mismas que permiten a unos Estados cumplir con mucha facilidad los compromisos convencionales y a otros con dificultades mayores y menores.

Tales dificultades permiten la adopción de distintas velocidades para que los Estados miembros alcancen el umbral mínimo exigible a todos en un debido tiempo: menor para aquellos miembros con mayores potencialidades; y mayor para los Estados miembros que requieren de esfuerzos mayores y hasta del respaldo subsidiario de la comunidad y de los Estados socios en el proceso.

El concepto de umbral mínimo no es solamente aplicable a los Estados miembros que requieren de mayores esfuerzos para lograrlo y que hasta que lo consigan, pueden ser dispensados de cumplir con determinadas normas comunitarias relativas a los objetivos comunes comunitarios, sino también cuando los requerimientos previstos en el umbral mínimo han sido superados por un particular Estado miembro, que debe hacer ajustes para evitar involuciones. En estos caos, el Estado con mayores potencialidades que las exigibles dentro de los umbrales mínimos, esperaría ser "alcanzado" por sus Estados socios en el proceso o se comprometería a cambiar sus políticas y estrategias nacionales, hasta hacerlas coherentes con las políticas y estrategias comunitarias.

La misma ductilidad del proceso de integración, suele dejar abierta la posibilidad de adhesiones posteriores, cuya filosofía se acerca a la que conforma los umbrales mínimos, puesto que cuando un Estado no miembro de la comunidad, pero interesado en serlo, ajusta sus políticas y estrategias o hace esfuerzos mayores, alcanzaría los requisitos que son exigibles para formar 
parte de la comunidad o para adherirse a un programa específico de la misma.

En esta posibilidad anterior se cifra también la ya mencionada conveniencia nacional, que determina las consideraciones y apreciaciones previas que debieron hacer los Estados para adherirse a la comunidad o a un determinado programa de la misma. Tal conveniencia, en la práctica se traduce en los mayores derechos y facultades establecidos en las normas comunitarias, como otra de sus características esenciales.

Las normas comunitarias no suprimen los derechos y las facultades nacionales, las magnifican hasta el punto de hacer incuestionable la conveniencia nacional. Ser ciudadano andino, por ejemplo, multiplicaría los derechos y las facultades inmanentes a la nacionalidad ecuatoriana, siguiendo el ejemplo propuesto, derechos y facultades que al Estado ecuatoriano le conviene conceder a sus nacionales.

Los mayores derechos y facultades se manifiestan en ciertos ámbitos y dentro de los límites de las competencias comunitarias. De hecho las "conveniencias" nacionales se hacen evidentes en esos ámbitos determinados, para alcanzar, por ejemplo, mayores derechos políticos, los atinentes a una ciudadanía comunitaria, por esencia mayor que la ciudadanía nacional; a las ventajas de un mercado ampliado; y a la libre circulación de personas y vehículos dentro de un área que toca lo regional, no meramente nacional, etc., etc.

Los ámbitos de las normas comunitarias están estrechamente determinados por los objetivos comunes, que a su vez alimentan las políticas comunitarias, y se determina, tales ámbitos, de conformidad con las competencias comunitarias, que alcanzan ámbitos específicos, relacionados con las materias previstas en los objetivos y en las políticas comunitarias, que a su vez se expresan en estrategias y acciones de la misma índole, por esencia "comunitarias". 
Siendo esta competencia otra característica fundamental de las normas comunitarias los límites de las competencias y los ámbitos de aplicabilidad de las normas, están precisamente determinados, aun cuando esta competencia no sea expresa, que es aquella descrita con términos y alcances específicos, sino la llamada implícita, que es la que se deduce de un objetivo y de una política comunitaria, como decir por ejemplo una norma de mercado interno, que aun cuando no se diga que su ámbito es comunitario, es evidente que la política de sustento alcanza al todo comunitario, sin excepción que no fuera, esa si específicamente determinada, debida a las distintas potencialidades nacionales.

Las competencias comunitarias, expresas o implícitas, guardan un equilibrio y una armonía dictada con los principios de competencias nacionales, especialmente en lo que tienen que ver con las recíprocas subsidiaridad, pertinencia y conveniencia de las normas comunitarias y de las nacionales sobre una misma materia o sobre materias conexas.

Cuando se trata de una materia específica, que haya sido determinada en los convenios, en las resoluciones en los programas y estrategias, como exclusiva de la comunidad, es cuando la competencia que los Estados miembros quieren que la comunidad tenga sobre esa materia sea exclusiva, entonces los ordenamientos nacionales deberán remitirse a la norma comunitaria, de ámbito comunitario.

En otras materias podrá haberse previsto una normativa comunitaria y normas nacionales coherentes, entonces se hablará de una competencia compartida, entre la comunidad y los Estados miembros.

Asimismo, es posible que una norma nacional específica necesite del respaldo de una norma comunitaria, entonces, la competencia dada a la comunidad será una de apoyo.

Desde un punto de vista del Estado nacional, es igualmente válida la clasificación, puesto que tal Estado se habrá reservado competencias exclusivas, compartidas y de apoyo, con relación 
a las normas comunitarias, exclusividad compartimiento y apoyo que no necesariamente tienen que ver con una subsidiaridad.

En materia de normas comunitarias, en conclusión, la competencia exclusiva no deja a lugar a la coexistencia de normas nacionales, ni siquiera subsidiarias; las que si, eventualmente, podrían ser consideradas, en algunos casos, cuando existan las llamadas competencias compartidas, que están en igual grado siendo tales desde tanto desde el punto de apreciación de la comunidad, como del Estado nacional. Tampoco pueden ser subsidiarias las normas comunitarias de apoyo a normativas nacionales, como resultaría impropio considerar subsidiarias a normas nacionales de apoyo a normas comunitarias.

En el respeto a las competencias de la comunidad y de los Estados miembros podría estar la clave del éxito para lograr el cumplimiento efectivo de las normas comunitarias, no solo porque son evidentemente convenientes para los Estados socios del proceso de integración, sino por haber un compromiso convergente de los Estados miembros de conceder esa exclusividad, o el compartir para la cabal aplicación de una norma o incluso la obligación de la comunidad de apoyar los respectivos ordenamientos nacionales.

\section{ALCANCES DE LA COMPETENCIA COMUNITARIA}

Si se admite que el núcleo de la cuestión relativa a la marcha de un proceso de integración está precisamente en el respeto a las competencias comunitarias, no solo es importante determinar los límites de las competencias, fueren exclusivas, compartidas y de apoyo, sino los mecanismos con los que cuente la comunidad para hacer valer las normas comunitarias, que deben estar conformes con los tantas veces mencionados objetivos comunes; que deben, las normas, responder a estrategias; y que tienen que afincarse en compromisos de los Estados partes, exigencias que no son similares a las que rodean a las normas jurídicas nacionales. 
Con la mención a los mencionados mecanismos comunitarios, para respaldar las normas respectivas, me refiero a los sistemas que deben haberse previsto para el arreglo de diferencias que puedan surgir y para corregir desequilibrios debidos a los efectos directos de las normas comunitarias, sobre los particulares.

Los mecanismos comunitarios se deben aplicar sin importar que las competencias comunitarias hayan sido expresas o implícitas, puesto que inclusive dentro de estas últimas, no parece suficiente determinar las materias conexas con la específica que determinó el señalamiento de una competencia comunitaria expresa, que se supone cuenta con el correspondiente mecanismo de sustento, sino que la competencia implícita podrá requerir también de controles.

Los controles mencionados en el párrafo anterior, están vinculados con la materia conexa, que puede identificarse como tal, como conexa, por la forma, el contenido, el funcionamiento y el alcance de los efectos directos de las normas comunitarias que rigen esas materias conexas. Los controles propios de las mismas podrían ser utilizables para aplicarse como mecanismo de respaldo a la materia principal, de las que son conexas, pero pueden haber variaciones, para apuntar más a la necesidad de proteger la materia principal.

Por ello es que los mecanismos y los controles no solo que suelen determinarse en los respectivos tratados y en proyectos comunitarios específicos, que son las dos fuentes más claras de concesión de competencias, sino que deben haberse concebido con la previsión de los recursos mínimos para ponerse en marcha y en esa tarea debe haber una estricta proporcionalidad entre los instrumentos previstos y los resultados de los mismos, para hacer las debidas correcciones, ampliaciones sobre sus alcances y otros ajustes y enmiendas.

La complejidad de la determinación de estas competencias implícitas, tendría que justificar la creación de órganos 
comunitarios de interpretación obligatoria, a los que los Estados miembros y los particulares de la comunidad pueden acudir para dilucidar la naturaleza de las materias.

Las materias que dan lugar a competencias expresas, en la práctica, son mucho más fáciles de determinar, porque están señaladas en los objetivos compartidos y en los proyectos comunitarios. En estos casos son más atendibles las diferenciaciones entre derecho comunitario originario y derecho comunitario derivado, que pueden ser útiles para derivar las consecuencias relacionadas con las responsabilidad de los Estados partes frente a las normas comunitarias de una u otra vertiente.

\section{FUENTES DE DERECHO ORIGINARIO Y DE DERECHO DERIVADO}

Hecha la salvedad relativa a la utilidad práctica de la anterior clasificación, cabe insistirse en que tanto las normas de derecho originario como derivado, responden a los mismos principios generales de proporcionalidad, solidaridad, equilibrio institucional y no discriminación, que no podrían clasificarse con grados mayores o menores de exigibilidad de la norma comunitaria, pero probablemente si cierta jerarquía jurídica, similar a la existente en ordenamientos jurídicos nacionales, con la aclaración de que siendo las comunitarias una normas que están ligadas a procesos, esos procesos se supone que por esencia cambian, avanzan o se estacan y modifican, según los impulsos políticos que reciben de los Estados socios de los procesos de integración.

Siendo así una primera jerarquía que podría concederse a las normas comunitarias que derivaron de los tratados fundacionales, no necesariamente pudieron permanecer vigentes por la marcha natural del proceso establecido en esos tratados fundacionales. Las primeras normas tendrían que, en 
consecuencia, haber cedido el paso a las provenientes de los tratados modificatorios, y quizás esas primeras normas de los tratados fundacionales deberían sino perdieron vigencia, como por el efecto de los tratados modificatorios, pudieron haber cambiado sus ámbitos y alcances por los tratados complementarios.

De cualquier manera, serían consideradas como fuentes del derecho originario, los tratados fundacionales, modificatorios y complementarios, para definir como fuentes propias del derecho derivado, los reglamentos, las directivas, las decisiones, las resoluciones, los informes, las declaraciones y los programas de acción que precisamente devienen de las normas comunitarias del llamado derecho originario.

Las normas comunitarias de derecho derivado responden, en consecuencia, a las facultades legislativas autónomas de los órganos legislativos comunitarios y se encuadran en distintos marcos de aplicación, de manera tal que una norma de derecho derivado será de aplicación general, para toda la comunidad, y otras podrían ser de aplicación específica.

Los marcos de aplicación están directamente vinculados con la obligatoriedad de las normas comunitarias, de manera tal que las de aplicación general son asimismo generalmente obligatorias para toda la comunidad, mientras que ciertas directivas y decisiones podrían ser solamente obligatorias para los Estados para los que están dirigidas.

En una línea similar, ciertas decisiones, aun cuando generales, podrían significar únicamente dictámenes, que constituyen sugerencias fundamentadas sobre una referencia determinada, que por la naturaleza de todo dictamen no resulta vinculante.

Por último, los programas de acción, los proyectos, no son obligatorios sino para los Estados partes del programa, que voluntariamente han accedido al mismo, aun cuando dicho proyecto o programa responda a objetivos compartidos por toda la comunidad. 
Una fuente que paulatinamente va tomando importancia es la que se refiere a la jurisprudencia, y que es fuente adecuada para el derecho originario y para el derivado. La importancia creciente se debe al involucramiento de los órganos de justicia nacionales para aplicar normas comunitarias que suelen resultar más completas y genéricas, al punto que la normativa comunitaria ha logrado alcanzar una vigencia independiente del grado de desarrollo de un determinado proceso de integración. Los ejemplos de aplicación de normativas andinas, por ejemplo, siguen siendo en los países de la subregión de una aplicabilidad mayor que el avance propio del proceso de la CAN.

En otros ámbitos, parte de los mecanismos de apoyo de las normas comunitarias está en la obligada aplicación de estas por parte de jueces ordinarios nacionales, como colofón a un principio de primacía, del que me ocuparé en párrafos siguientes.

En conclusión, la jurisprudencia de órganos comunitarios resulta tan recursiva como fuente del derecho comunitario, como la jurisprudencia de tribunales nacionales. Debido a que, lógicamente, los órganos jurisdiccionales comunitarios son creados por tratados específicos y a que reciben las debidas competencias de los Estados miembros de la comunidad, en algunos procesos la jurisprudencia comunitaria es escasa, no así, como contraste y según expuso en párrafos anteriores, la jurisprudencia que viene de organismos jurisdiccionales nacionales.

Las posibilidades ciertas de que los órganos competentes, no únicamente jurisdiccionales, de la comunidad pueda emitir reglamentos y directivas, puede llegar a constituir tales reglamentos y directivas, especialmente si no están dirigidas a un destinario en particular (un Estado o un particular) también una suerte de fuentes del derecho comunitario, que han merecido el calificativo de sui generis, porque no son las usualmente previstas en tratados. 
En lo que toca a estas llamadas fuentes sui-generis si cabrían hacerse distinciones sobre el grado de obligatoriedad de las mismas de manera tal que serían generalmente obligatorias las provenientes de reglamentos, de aquellos que establezcan procedimientos internos a los que es menester acogerse, y las que provengan de decisiones comunitarias generales, que no tengan un destinatario determinado; así como serían usualmente fuentes suigeneris de normas no obligatorias, las que provengan de resoluciones, de informes, de declaraciones y de programas de acción común.

Una última categoría de fuentes del derecho comunitario consistirá en las llamadas fuentes supletorias, que merecen consideraciones particulares debido a los trámites que merecerían llevarse a cabo para estas fuentes supletorias lleguen a influir en la formulación de normas comunitarias.

Así, el Derecho Internacional Público, considerado como la fuente supletoria principal, podría ser la inspiración de normas comunitarias que recogen los ordenamientos de alcance universal del Derecho Internacional Público, en materias que interesan a todos los miembros de la llamada comunidad internacional, cuyos miembros demuestran tanto mayor interés o similar interés que el que tales ordenamientos de alcance universal suelen despertar entre los Estados miembros de una comunidad inmersa en un proceso de integración.*

Las otras fuentes supletorias tienen validez más relativa que el Derecho Internacional Público, por ejemplo los derechos nacionales, usualmente mencionados como fuente supletoria, porque es cierto que las normas comunitarias pudieron haberse nutrido de ordenamientos jurídicos nacionales, pero sólo en la medida de que tales ordenamientos nacionales tuvieren suficientes elementos comunes para poder proyectarse en ámbitos regionales. Caso contrario, los ordenamientos jurídicos nacionales son más bien obstáculos para el acatamiento de normas comunitarias, que 
se suelen presentar como promulgadas exprofesamente para ser tales, no como elaboraciones de particulares normas nacionales.

Igual ocurre con la costumbre, también señalada como fuente supletoria, porque debe responder a una conducta comúnmente repetida en todos los ámbitos domésticos de los Estados miembros y no obedecer a imposiciones de miembros más conspicuos.

En mi opinión tienen mayor valor como fuentes supletorias del derecho comunitario los principios generales de derecho, que son una base fundamental en la génesis del derecho comunitario y la doctrina científica, por la incuestionable influencia académica en los distintos procesos de integración que llevan a las comunidades, que se han preocupado de elaborar y llevar a la práctica propuestas que fueron originalmente ideales.

\section{REQUiSITOS PARA LA APLICABILIDAD DE LAS NORMAS COMUNITARIAS}

En el proceso de hacer realidad ideales integracionistas de las comunidades, fue necesario descender a la práctica, para evitar convertir a las propuestas pertinentes en simples proclamas, que nunca se cumplieron a cabalidad o que incluso cuando se emitieron, no se tenía la intención real de efectuarlas.

Para ese paso fundamental de lo retórico a lo práctico, se tienen que establecer requisitos para que una norma comunitaria tenga aplicabilidad y vigencia: requisitos que tienen que ver con el carácter de las normas; con su inserción en los ordenamientos nacionales de los Estados miembros de la comunidad; con el efecto directo de las normas; con sus características; con la justificación jurídica de su obligatoriedad; con la estructura de las normas comunitarias; y con los procedimientos generados por las mismas.

Es menester tomar en cuenta que el derecho comunitario es una creación de la comunidad, pero al mismo tiempo ese derecho 
es la base del sistema institucional de la comunidad. De manera distinta a lo que ocurre con las normas de ordenamientos jurídicos nacionales, la fuerza del derecho comunitario está en su propia constitución como tal, como derecho, y al igual que en los ordenamientos nacionales, en los sistemas creados por la comunidad para proteger a la norma comunitaria, derecho y sistemas nacidos de un compromiso político compartido, tan estable y permanente como los Estados miembros quieren que sea.

Nuevamente con la concepción de tal compromiso político de los Estados miembros, puede plantearse la primacía del derecho comunitario sobre las normas de derecho nacionales de los Estados miembros de la comunidad y esa primacía puede haber sido expresamente reconocida por los Estados miembros, incluso a través de disposiciones de sus Constituciones o se acondiciona, la primacía, a principios fundamentales recogidos por las Constituciones de los Estados miembros.

Fuere, entonces, la primacía de las normas comunitarias reconocida expresamente o si se tratara de una conformidad de la primacía con principios fundamentales constitucionales, de esos Estados, lo importante es que el alcance de la primacía sea general, es decir que abarque a toda la comunidad.

Este alcance toma una dimensión práctica en la aplicación de la norma a todo el universo comunitario y para lograrla se hace necesario un órgano comunitario encargado de velar por el principio de primacía, ese órgano debe hacer sido previsto en los tratados fundacionales, modificatorios o complementarios, y debe estar acompañada de una acción comunitaria, igualmente aceptada por los Estados miembros. El órgano comunitario encargado de velar por el principio de primacía, debe contar, en consecuencia, con suficientes facultades para sancionar a los Estados que incumplan con este principio.

Las facultades de sanción son aceptadas por compromisos convencionales recíprocos, planteados expresamente en convenios entre los Estados partes. Usualmente se establecen escalas en las 
sanciones, para ir de la llamada la atención al Estado omiso; pasar por la exhortación y llegar hasta plantear un proceso de separación voluntaria del Estado incumplido, con la justificación de que a todas luces no está lo suficientemente dispuesto a acatar el principio, cuyo incumplimiento afecta, en mayor o menor grado, a toda la comunidad.

Estos compromisos de los Estados miembros suelen depender de un equilibrio cabal entre las facultades soberanas nacionales y las competencias concedidas a la comunidad, por ello, por este equilibrio, usualmente se permite una doble inserción de la norma comunitaria en los ordenamientos nacionales. Una inserción directa, que no prevé procedimiento alguno de recepción, y una inserción que se demuestra por la ejecución de la norma comunitaria por cada Estado miembro y de conformidad con su arbitrio procesal.

Por supuesto que el mérito mismo de la norma comunitaria es el que justifica la inserción en los ordenamientos nacionales, que reconocen que la norma comunitaria tiene ese ineludible efecto directo, que implica en términos prácticos el derecho de los particulares a pedir que los jueces nacionales acojan y apliquen la norma comunitaria, puesto que ésta ha concedido en realidad derechos y obligaciones de manera directa, sin tener que pasar por el endoso o la ratificación de una norma nacional.

El efecto directo de la norma comunitaria funciona de manera vertical, de los particulares a los Estados miembros, y de manera horizontal, entre particulares. La experiencia acumulada por la Unión Europea ha hecho ver que el efecto directo vertical es mucho más fácil de aplicar, que el horizontal.

Para que la norma comunitaria logre este efecto directo, debe llenar algunas características, que tienen que ver con la forma, el contenido, la función, y la naturaleza de la norma, las mismas que dan lugar a la obligatoriedad de la misma, que nace del derecho originario (tratados fundacionales, modificatorios y complementarios) y, dentro del llamado derecho derivado, de los 
reglamentos autónomos y de ejecución; de las directivas, que si tendrían necesidad de un proceso de recepción; de las decisiones a destinatarios precisados; y de los actos convencionales, relacionados con los convenios de aplicación, con los convenios ligados a la ejecución, con las decisiones de los órganos comunitarios competentes y con los convenios perfeccionados entre la comunidad y terceros.

Las características descritas en el párrafo precedente convierten en obligatoria la aplicación de la norma comunitaria cunado sea reclamada por un particular a un juez nacional de un Estado miembro. Si la norma no tuviere estas características, un particular puede alegar su aplicación, pero el juez requerido no estaría obligado a acoger la alegación del particular.

El punto medular de la obligatoriedad de la norma comunitaria está en la responsabilidad que acarrea para el Estado miembro su incumplimiento El particular denuncia que el Estado no ha protegido los derechos y las obligaciones concomitantes implícitas en una norma comunitaria determinada y esa desprotección acarrea el derecho del particular a recibir una reparación om una indemnización por el daño sufrido.

Para la configuración de la responsabilidad del Estado tendrán que verse, por supuesto, los fines y los objetivos de la norma comunitaria; sopesar los derechos y las obligaciones efectivas concedidos por ella a los particulares; tendrá que tomarse en cuenta el con tenido de la norma comunitaria y, sobre todo, deberá establecerse una relación de causalidad entre el incumplimiento denunciado y el daño causado por el mismo a un particular.

Debida a la misma estructura de la norma comunitaria, la justificación de su obligatoriedad, que debe reconocerse como el punto medular, se cifra en el mérito del derecho, por haberse promulgado en aras de la libertad, la igualdad y la equidad referida a los Estados miembros de la comunidad y a los particulares y por ese mérito intrínseco de la norma haber dado 
lugar al sistema de protección previsto por la comunidad, tanto para resolver conflictos por su aplicación, cuanto para velar por su cumplimiento.

El doble objetivo del sistema de protección de la norma comunitaria envuelve al Estado miembro que se compromete a adoptar medidas para cumplir los tratados, cumplir las obligaciones que provengan de los actos de los organismo comunitarios y cumplir las resoluciones pertinentes. Este compromiso recíproco, soberano y voluntario de los Estados miembros, conforma los contornos de su responsabilidad ante la comunidad y ante los ciudadanos, que también están envueltos en el proceso de consolidación de la comunidad.

Formalmente la obligatoriedad, previamente comprometida por los Estados, aparece en los instrumentos jurídicos de la comunidad, sus reglamentos, las decisiones generales e individuales,, las directivas y las recomendaciones.

Por lo anotado, los grados de obligatoriedad pueden ponerse en un primer nivel, que responde a los tratados de todo tipo que conforman el derecho originario y a los instrumentos propios del derecho derivado: a saber reglamentos, directivas, decisiones y los actos convencionales para aplicar y ejecutar las decisiones y los convenios con terceros; y en un segundo nivel de obligatoriedad, que se acerca más a una sugerencia, relacionada con las normas sui generis, las complementarias y las supletorias.

\section{ESTRUCTURA DEL DERECHO COMUNITARIO}

Todos los elementos descritos confirman que el derecho comunitario no es un derecho internacional y aun cuando para aplicabilidad requiera de ordenamientos jurídicos nacionales, no tiene las características esenciales de los derechos nacionales ni puede considerarse como una suma de los mismos. El derecho comunitario, dije en párrafos anteriores, es la base del sistema institucional de la comunidad y es al mismo tiempo una creación 
de la misma, el valor de la norma descansa en el valor del mismo derecho.

Los actos jurídicos que conforman el derecho comunitario son actos vinculantes que crean derechos y obligaciones y que se apoyan en un sistema de protección, también creado por la comunidad, con el doble propósito de resolver conflictos y para poder velar por el cumplimiento de la norma comunitaria, que configura o que establece una relación de la comunidad con los Estados miembros y de los Estados miembros con los individuos, por ende la responsabilidad de los Estados, por ser miembros de la comunidad, se proyecta hacia la misma comunidad, considerada como un todo, y hacia los individuos.

Esa responsabilidad asumida por los Estados miembros se hace patente en la adopción de medidas para cumplir con las obligaciones derivadas de tratados y de normas obligatorias; los Estados miembros están también comprometidos a abstenerse de realizar toda acción u omisión, que pueda poner en riesgo los compromisos convencionales y las normas obligatorias; y los Estados miembros asumen, finalmente, la responsabilidad que les corresponda por los perjuicios que los incumplimientos pueda causar a los ciudadanos de la comunidad.

Bajo esas concepciones fundamentales, el sistema jurídico de protección comunitaria tiene que establecerse: primero, sin que deba depender de la voluntad de los Estados miembros; en segundo lugar, para que no interfiera en los ordenamientos jurídicos nacionales; y en tercer término, si debe tomar en cuenta que el sistema comunitario de protección no contradiga normativas nacionales.

Las fuentes del sistema de protección, por obvias razones, son las mismas que las fuentes del derecho comunitario positivo; es decir, los tratados, las decisiones generales; los reglamentos; y las leyes comunitarias.

Siguiendo la misma lógica, por regla general la aplicación del sistema debe ser total, no parcial, el sistema debe ser válido de 
manera uniforme e íntegra; y especialmente, debe tener una aplicabilidad directa, lo que significa que no tiene necesidad de contar con una normativa nacional, y la protección de los derechos y las obligaciones se deberá hacer frente a los tribunales, a las autoridades y a los individuos.

El sistema de protección está compuesto de normas comunitarias de protección, puede obedecer también a resoluciones de los órganos competentes comunitarios, resoluciones éstas que pueden ser generales, o de validez individual, esto es con una determinación de los destinatarios, pueden ser resoluciones no vinculantes, por ejemplo dictámenes y, finalmente, pueden referirse a programas de acción, que hemos dicho comprometen únicamente a los Estados miembros participantes.

Aparte de las normas comunitarias y de las resoluciones, descritas en el párrafo anterior, el sistema de protección se nutre de directivas que acercan las normas comunitarias a los ordenamientos nacionales. La eficacia de las directivas está en fijar metas, según los objetivos comunitarios, y abrir la puerta a los procedimientos nacionales.

Con referencia a los objetivos comunitarios es que, en cuanto a la aplicabilidad del sistema los destinatarios del mismo pueden ser, en unos casos, todos los Estados, en otros varios de ellos y cabe la posibilidad de que el sistema sea recomendado sólo a un Estado miembro.

En esta materia del destinario del sistema, es dable aplicar la llamada transposición que permite la ejecución del mismo en cada Estado miembro y permite que sea ese Estado el que elija los medios para hacerlo.

Sea cualquiera el método utilizado por los Estados para adoptar el sistema comunitario de protección, con el acto de ejecución de las normas que conforman dicho sistema se abre la posibilidad de que los particulares, empresas o individuos, puedan expresar formalmente su oposición ante los tribunales nacionales. 
La oposición al sistema no necesariamente debería sustentarse en los perjuicios que las empresas y los individuos expresen, con fundamentos, que el sistema podría provocarles, pero aunque la mayor parte de las veces si se debe precisamente a los perjuicios por lo que se demanda la oposición al sistema, las demandas a los tribunales nacionales se pueden hacer también porque falta claridad normativa, porque no existe vinculación entre la norma y el sistema, por la imposibilidad de fijar el contenido de la norma o por haberse vencido un plazo prudencial para llevar adelante la transposición. Lo importante termina siendo que el efecto directo sancionador resulte coherente con las acciones de reclamo concedidas a los particulares.

\section{LOS PROCEDIMIENTOS DEL DERECHO COMUNITARIO}

Todo lo hasta hora examinado nos lleva concluir en que los procedimientos del derecho comunitario son más o menos iguales fuere para crear las normas comunitarias o para establecer los mecanismos del sistema de protección. El derecho comunitario, entonces, tiene dos componentes fundamentales en cuanto a procedimientos se refiere, el normativo y el relativo a los mecanismos de protección.

Los procedimientos, normativo y de protección, representan la facultad legislativa de la comunidad, la misma que encuentra similitudes con los procedimientos legislativos nacionales, cuando el pueblo se hace representar en los Parlamentos, más o menos de la misma forma como los Estados miembros se hacen representar en los órganos legislativos comunitarios.

En los procesos legislativos nacionales, la soberanía popular está mucho más claramente representada por los legisladores, mientras que los legisladores comunitarios más se acercan a representar a sus Estados que a los individuos, puesto que son los Estados los que se comprometieron en el proceso de integración y toda vez que como tales, como Estados, asumen responsabilidades 
para hacer cumplir las normas que produzcan los legisladores comunitarios.

El proceso de legislación comunitario, a diferencia de los actuales procesos legislativos nacionales, es uno que responde claramente a etapas sucesivas, una primera etapa, en la que antes de contar con órganos legislativos comunitarios, los Estados miembros desarrollaron acciones de armonización de las distintas legislaciones nacionales; cumplieron tareas de coordinación legislativa; concertaron las políticas nacionales con las políticas comunitarias; y, dentro de esa primera etapa, los Estados llevaron a cabo consultas vinculantes con el órgano legislativo comunitario.

Esa primera etapa debe dar lugar a la segunda, en la que los Estados miembros conceden competencias legislativas a órganos comunitarios y que debería consolidarse, como etapa, cuando tales órganos comunitarios asuman facultades legislativas plenas, que en algunos procesos están menos que delineadas, como ocurre con el Parlamento Andino que oficialmente no es un órgano legislativo, sino meramente deliberante.

Las facultades legislativas comunitarias se manifiestan en 3 niveles, uno que corresponde a los actos jurídicos vinculantes, cuya competencia obedece a tratados y resoluciones de los órganos superiores comunitarios y de los órganos legislativos y que los procedimientos respectivos aparecen en reglamentos; un segundo nivel relativo a las medidas comunitarias de ejecución, que están generalmente a cargo de órganos comunitarios superiores, o de otros órganos previstos en programas de acción y en proyectos; y un tercer nivel presente en los actos administrativos, que en la mayoría de los casos son de responsabilidad de los Estados miembros.

La mecánica descrita hace ver que la iniciativa legislativa suele corresponder a los órganos comunitarios superiores, a las comisiones técnicas de los mismos y en virtud al avance del proceso de integración, a órganos legislativos comunitarios. 
Las fases legislativas comunitarias se parecen a las legislativas nacionales. Una vez conocida la iniciativa, se va a un debate sobre sus objetivos y alcances, para pasar a la realización de consultas con comités y comisiones comunitarias, con grupos de activistas y con las ciudadanías de los Estados miembros. Los órganos legislativos comunitarios suelen contar con informes $\mathrm{y}$ dictámenes.

La iniciativa puede, en conclusión, terminar por ser aprobada o rechazada y en el medio de las dos alternativas mayores, podría devolverse al órgano comunitario proponente de la iniciativa, para que la modifique de alguna forma.

De haberse aprobado la iniciativa, ya convertida en norma comunitaria, suele ser devuelta a un órgano de ejecución comunitario que hará los trámites para la publicación de la norma en un diario o gaceta de la comunidad y en diarios o gacetas oficiales de los Estados miembros.

La corresponsabilidad por la aprobación de la norma queda radicada en el parlamento u órgano legislativo comunitario, en los consejos, en las comisiones y en otros órganos previstos en tratados específicos.

\section{EL DERECHO DE INICIATIVA LEGISLATIVA EN EL ORDENAMIENTO COMUNITARIO}

Las particularidades de la comunidad, que hasta cuando en un futuro indefinible, termine por convertirse en una nueva entidad política distinta a la de los Estados, si esa sería la meta final de una integración, hace que el derecho de iniciativa, para la creación de normas comunitarias, también esté dispuesto principalmente en tratados y cuando el proceso se haya puesto en marcha, en resoluciones de los órganos comunitarios competentes.

Igualmente se hace evidente que los Estados miembros participantes tienen un derecho de iniciativa legislativa a través de programas y proyectos comunitarios.

Ius Humani, v. 2 (2010/11), p. 134 
Recién cuando las competencias concedidas por los Estados miembros a los órganos legislativos comunitarios se hayan consolidado, el derecho de iniciativa corresponderá a los parlamentos comunitarios, que tendrán que tener una relación de equilibrio con los órganos superiores y con los órganos ejecutivos comunitarios, que recibirían de los parlamentos comunitarios las normas que deberían poner en marcha.

El punto relativo al derecho de iniciativa legislativa de los ciudadanos comunitarios, merece una especial consideración porque no necesariamente las ciudadanías deberían esperar por la consolidación de las facultades legislativas de los parlamentos comunitarios, puesto que desde los inicios de un proceso de integración ya se hace evidente la participación ciudadana, a través de sus propios mecanismos (grupos activistas, comités, etc.), participación ésta que será mucho más institucionalizada cuando las ciudadanía tengan sus propios representantes parlamentarios, a nivel comunitario.

Estrechamente vinculado con el proceso de creación de normas comunitarias, está el sistema relativo a las medidas de ejecución de las mismas. Mencioné antes el procedimiento que se espera seguir cuando una iniciativa legislativa se ha convertido en norma, cabe ahora determinar que antes de que puedan caber las devoluciones, por parte de los órganos legislativos comunitarios a los órganos superiores y a los ejecutivos comunitarios, en una primera instancia pueden existir disposiciones comunitarias previstas en los tratados, fundacionales, modificatorios o complementarios, que deberían ser ejecutadas por los órganos nacionales previstos por los Estados miembros en los tratados.

Fuere que las normas comunitarias hayan sido comunicadas directamente, en virtud a los tratados según la posibilidad explicada en el párrafo anterior, o ya con parlamentos comunitarios en funciones, una vez que la norma comunitaria sea recibida por un órgano comunitario superior, cabe el reenvío de la 
norma de ese órgano superior a niveles inferiores, para lo que se utilizan directivas e instrucciones.

En una final posibilidad, también anunciada en párrafos anteriores con relación a programas y proyectos comunitarios, las medidas de ejecución serán adoptadas para ir a órganos de ejecución previstos en los proyectos y a mecanismos de seguimiento.

\section{LOS RECURSOS EN EL DERECHO COMUNITARIO}

Para completar la estructura del derecho comunitario, que he descrito en sus fases normativas y en las relacionadas con el sistema jurídico de protección, cabría analizar el conjunto de recursos que especialmente los particulares pueden tener, para evitar que las normas comunitarias sean solo enunciados de buenas intenciones de los Estados miembros y para que los compromisos asumidos por los mismos, por los Estados miembros, se orienten a asegurar la vigencia y plena aplicabilidad de las normas comunitarias.

La enumeración y explicación somera de estos recursos podría ser criticada por responder más a la doctrina, que no siempre es suficiente para evitar los incumplimientos de los Estados miembros, pero si bien se debe reconocer que no todos estos recursos son comunes en todos los procesos de integración, muchos de ellos sin son comúnmente aceptados como útiles, para hacer vigentes y plenamente aplicables a las normas comunitarias.

Un primer recurso estaría relacionado con un incumplimiento de un Estado miembro, cuando el recurso debe presentarse ante un órgano jurisdiccional comunitario, el que concede al Estado acusado la oportunidad de responder la denuncia. El actor puede ser un órgano comunitario superior y otro Estados miembro perjudicado. La sentencia del órgano jurisdiccional comunitario implicará la obligación para el Estado 
incumplido de subsanar la deficiencia acusada y cabe también la posibilidad de establecer una multa coercitiva.

Un segundo recurso consistiría en perseguir la anulación de un acto jurídico vinculante, para lo cual la demanda deberá presentarse ante un órgano jurisdiccional nacional por parte de individuos o de empresas, que serían los actores apropiados. Cabe también doctrinariamente la posibilidad de que el actor sea un órgano comunitario, entonces la demanda deberá presentarse ante un órgano jurisdiccional comunitario. Las causas para la demanda pueden ser la incompetencia del órgano que promulgo la norma comunitaria tachada; el incumplimiento o la violación de procedimientos legislativos; o los daños provocados por la norma a individuos o empresas. La sentencia respectiva, de acogerse la demanda, sería la nulidad del acto jurídico vinculante, con efectos retroactivos al tiempo en que la norma anulada fue promulgada y por supuesto tendrá también efectos posteriores a la promulgación de la sentencia.

El tercer recurso es por omisión denunciada por un órgano comunitario superior contra un órgano ejecutivo comunitario. Ordinariamente, el actor es el órgano superior que acude ante un órgano jurisdiccional comunitario para demandar la omisión del órgano ejecutivo, pero cabe también que la omisión sea denunciada por individuos o empresas ante un órgano jurisdiccional nacional. La causa tiene que ser relativa a que el órgano ejecutivo comunitario competente no tomó las medidas para que se aplique el acto jurídico vinculante, omisión que perjudicó el cumplimiento el tratado o que causó daño a individuos o a empresas. La sentencia deberá orientarse al cumplimiento del acto jurídico omitido.

La indemnización, prevista como cuarto recurso, puede ser requerida ante un órgano jurisdiccional comunitario cuando el actor sea un Estado miembro contra otro Estado; o puede ser requerida ante un órgano jurisdiccional nacional por parte de individuos o de empresas. El objetivo básico de la demanda tendrá 
que ser el señalamiento de responsabilidades de un Estado miembro y los requisitos para interponerla serán la actuación contraria a derecho de un funcionario comunitario o de un juez nacional; la existencia de un daño; el nexo causal entre el daño y la actuación del funcionario o del juez nacional, con la aclaración de que esta actuación no debe ser necesariamente dolosa, puesto que caben considerarse las impericias.

El quinto recurso, la casación, siempre debe interponerse ante un órgano jurisdiccional comunitario por una violación del derecho comunitario o por perjuicio a los intereses del demandante. Según la doctrina al respecto, el efecto de la decisión del órgano jurisdiccional comunitario, que acoja la casación, sería el de anular la decisión del órgano jurisdiccional nacional; o la devolución del litigio al órgano jurisdiccional nacional, para que tome en cuenta la decisión; o podría ser que el mismo órgano jurisdiccional comunitario sea el que dirima la cuestión, si la causa estuviere sustanciada para que se ejecute.

En cuanto a medidas provisionales no parece haber mucha práctica de las mismas en el derecho comunitario latinoamericano y en el europeo se parte del principio de que un órgano jurisdiccional comunitario no puede suspender la ejecución de decisiones de tribunales nacionales, pero si puede pedir, el órgano comunitario, que sean los tribunales nacionales los que suspendan la ejecución. Los fundamentos para este sexto recurso giran en torno a la urgencia de evitar un daño irreparable al demandante, por lo que se supone que debe mediar una evaluación y para realizar esta evaluación, por lógica sería menester hacer un examen sumarial, ya que de ese examen se puede determinar las posibilidades reales de que las objeciones del demandante sean recogidas. Aparte de lo anotado, debería hacerse una ponderación de los perjuicios alegados por el demandante frente a los intereses de la comunidad y frente a los intereses de terceros, si la norma denunciada se cumpliera de inmediato. 
Un último séptimo recurso no es contencioso, en un recurso prejudicial que ha sido utilizado con frecuencia en el ámbito del derecho comunitario latinoamericano y en el europeo y funciona como una consulta de los órganos jurisdiccionales nacionales a un órgano jurisdiccional comunitario sobre la validez un acto jurídico que deba aplicarse. El órgano jurisdiccional comunitario, entonces, se pronuncia de forma vinculante, sobre la consulta formulada por un órgano jurisdiccional nacional que propone la aplicación de una norma, que el órgano comunitario consultado deberá decir si es aplicable, no aplicable o ilegítima; es decir, el órgano jurisdiccional comunitario confirma o niega la pertinencia de la norma sugerida. Como requisitos para presentar el recurso, doctrinariamente se establece que la consulta debe versar sobre una cuestión jurisdiccional que no tenga recursos de apelación o de casación y cuando los órganos jurisdiccionales nacionales, en principio hubieron estado persuadidos de que el acto jurídico propuesto no es válido.

\section{LA RESPONSABILIDAD DE LOS ESTADOS MIEMBROS POR INCUMPLIMIENTO DEL DERECHO COMUNITARIO}

Toda la estructura del derecho comunitario, descrita en este ensayo, encuentra plena justificación en la consolidación de un proceso de integración, que descansa en una identidad mayor a la de identidades nacionales de los Estados miembros y en la necesidad de establecer mecanismos para evitar, al máximo posible, los incumplimientos de los compromisos de esos Estados miembros, compromisos éstos que, no molesta insistirse en ello, se deben a una voluntad política que en la creación y mantenimiento de la comunidad, exigen una oferta cada vez mayor y una determinación de los Estados cada vez más sostenida.

Por lo menos en teoría, la mayor concesión de facultades a la comunidad, por parte de los Estados, no sólo que implicaría el 
aumento progresivo de las facultades de los órganos comunitarios, y el consiguiente debilitamiento de algunas facultades nacionales, sino también un involucramiento, igualmente progresivo de la responsabilidad de los Estados miembros.

Para cubrir la eventualidad de que esa responsabilidad vaya mucho más allá de un simple señalamiento de la misma sin consecuencias, en la doctrina del derecho comunitario la responsabilidad de los Estados aparece como corolario del efecto directo de las normas comunitarias y del nexo causal entre la norma y el daño que se alegue haberse sufrido. La responsabilidad encuentra su base de sustentación en el principio de primacía de las normas comunitarias y en la obligatoriedad de las mismas, a instancias de los derechos y deberes comprendidos en la norma, a todos los poderes de los Estados miembros, poderes éstos, que en sus respectivas órbitas, comprometen por igual al Estado al que pertenecen.

La concepción integral de la responsabilidad del Estado, en consecuencia, alcanza a las acciones y omisiones de todos los órganos del Estado, en cualquiera de las funciones fundamentales, porque se parte precisamente del indicado presupuesto de que la acción o la omisión infringieron los derechos otorgados por la norma a otros Estados y a los individuos de la comunidad.

No importa la gravedad de la infracción, puede ser una que haya dañado a los individuos y a las empresas de un Estado miembro o de tanta gravedad como para perjudicar el cumplimiento efectivo de un objetivo comunitario, que, en una medida mesurable, haya significado sobrepasar las facultades reservadas como competencia exclusiva o compartida del Estado miembro.

El más usual incumplimiento por el que un Estado miembro determinado debe asumir su responsabilidad, en la práctica se puede dar en los órganos jurisdiccionales nacionales, por sus sentencias y otras providencias en violación de una norma comunitaria, y en las acciones y omisiones de órganos 
comunitarios de ejecución. Menos posibilidades de incumplimiento podrá encontrarse, en la práctica, en los actos legislativos nacionales y, en similar situación, en los actos administrativos nacionales. Debido a esto, la concesión de recursos está más orientada a los individuos y a las empresas perjudicados y a los órganos comunitarios con facultades de dirección y control. Los individuos y las empresas persiguen la compensación de los Estados miembros señalados como responsables, mientras que los órganos comunitarios de control y dirección ordinariamente persiguen la corrección de la conducta comunitaria.

\section{EL ROL ACADÉMICO EN EL NUEVO ORDEN INTERNACIONAL}

El nuevo orden internacional, proyectado sobre estas concesiones de importancia a las contribuciones de los Estados Nacionales y en torno a la necesidad de contrarrestar las facultades implícitas que parecen reclamar tanto la potencia hegemónica como los Estados mayores que están rivalizando con ella, debería preocupar principalmente a los gobernantes y a los gobernados de los Estados pequeños, aquellos que sólo pueden tener remotamente acceso al círculo de poder de decisión o aquellos pequeños Estados que, aún en el supuesto de que lograran integrarse, constituirían una entidad inferior, que no resultaría influyente en los procesos de toma de decisiones de la Comunidad Internacional.

Por supuesto que entre los gobernados, se supone que deberían mostrar mayor atención los estudiosos y, así en cadena, más cercanos al problema deberían estar quienes pretendan hacer especializaciones en materias vinculadas estrechamente con ese nuevo orden que se vislumbra. Los contenidos del mismo pueden merecer investigaciones de estudiosos, individualmente considerados o en grupos. 
Por lo anterior es que las universidades y las instituciones de educación superior, tendrían que promover el análisis de estos relativismos actuales y de los principios que se supone que ordenan a la Comunidad Internacional del futuro próximo, máxime si no se discute que vivimos en una época de cambios esenciales y de nuevas realidades, que obligan a que los Estados y los particulares diseñan y planteen nuevos modelos y soluciones para problemas irresueltos en varias décadas anteriores, durante las cuales ocurrieron cíclicas actitudes de Estados y de tratadistas, para ensalzar los valores de la Comunidad Internacional o para rescatar el imperio de soberanías nacionales, en varios ámbitos.

El tema, desde un punto de vista meramente académico, giraría no sólo en torno al análisis de los relativismos que se han impuesto a los principios y a las reglas convencionales del Derecho Internacional Privado, sino que alcanzarían también a la búsqueda de esas soluciones para superar las eventuales causas de conflicto entre bloques de Estados y entre los nacionales de esos Estados coaligados o comprometidos con el bloque, así como los análisis críticos se desarrollarían con el propósito de proponer estrategias y acciones para conseguir la proyección internacional de las modelos y las soluciones nacionales, para que los Estados Nacionales promuevan alianzas efectivas e inclusive para la inserción adecuada de un Estado Nacional y de su región, en el nuevo mundo globalizado.

Sería útil para los Estados, para los nacionales y para los residentes extranjeros de esos Estados, que las conclusiones académicas sirvan a los gobernantes para promover caminos prácticos adecuados a fin de que las sociedades nacionales se enderecen por rumbos que, idealmente, podrían servir para incrementar la influencia real del país en la toma de decisiones de la Comunidad Internacional, o para que se tomen en cuenta las particularidades nacionales en los procesos de concertación y de integración, incluida la imparable globalización, o para que se aprecie en sus reales términos la incuestionable fragilidad de los 
Estados Nacionales, agravada por la preeminencia de potencias que disponen de instrumentos, hasta ahora válidos para ejercer presiones y hacer valer las conveniencias y los intereses de sus nacionales.

En consecuencia con lo anterior, la idea fundamental del papel de las universidades y otras instituciones de educación superior, estaría en dar forma a un nuevo concepto de responsabilidad en la marcha de la sociedad a la que deben servir. Los análisis de los expertos tendrían que provocar mayores análisis, investigaciones y proyecciones prácticas en los planificadores de políticas estatales. 


\section{REFERENCIAS}

Alonso García, R. (1997). Tratado de Libre Comercio Mercosur y Unión Europea. Madrid: MacGraw-Hill.

Arellano García, C. (2006). Derecho Internacional Privado. México DF: Porrúa.

Arjona Colomio, M. (1954). Derecho Internacional Privado. Barcelona: Bosch.

Balestra, R. (1968). Manual de Derecho Internacional Privado, Buenos Aires: Abeledo Perrot.

Boggiano, A. (1981). Del Viejo al Nuevo Derecho Internacional Privado. Buenos Aires: Depalma.

Boggiano, A. (1998). Derecho Internacional Público y Privado y Derecho del Mercosur en la Jurisprudencia de la Corte Suprema de Justicia de la Nación Argentina. Buenos Aires: Fondo Editorial La Ley.

Borchard, K.-D. (1999). El ABC del Derecho Comunitario (5 ${ }^{\text {a }}$ edición). Bruselas: Unión Europea.

Carrillo Salcedo, J.A. (1991). El Derecho Internacional en Perspectiva Histórica. Madrid: Tecnos.

Larrea Holguín, J. (1962). Manual de Internacional Privado. Quito: PUCE.

Lascano, C.A. (1965). Derecho Internacional Privado. Buenos Aires: Editorial Platense.

Mangas Martín, A. \& Liñán Nogueras, D. (2009). Instituciones y Derecho de la Unión Europea. Madrid: Tecnos.

Ortiz de la Torre, J.A. (1992). Derecho Internacional Privado, Parte General. Madrid: Editorial Complutense.

Pardo, A.J. (1976). Derecho Internacional Privado, Parte General. Buenos Aires: Abaco.

Pesantes García, A. (1977). Las Relaciones Internacionales (Derecho Diplomático y Práctica Diplomática). México: Ediciones Cajica.

Posso Serrano, A. (2007). Los relativismos de los principios de Derecho Internacional Contemporáneo. Quito: Universidad de los Hemisferios.

Romero del Prado, V. (1961). Derecho Internacional Privado. Santiago de Chile: Editorial Alessandri.

Ius Humani, v. 2 (2010/11), p. 144 
Sosa, G.L. (1996). El Derecho Internacional Privado Interamericano y el Derecho de Integración. Santa Fe: Tercer Milenio.

Verdross, A. (2000). Nuevo Derecho Internacional Privado. México DF: Themis.

\section{Normativa:}

Código de Derecho Internacional Privado Sánchez de Bustamante, VI Conferencia Panamericana, Habana 1928.

Tratados de Derecho Internacional Privado, 1889, 1939, 1940.

Convenciones Interamericanas vigentes: sobre Exhortos o Cartas Rogativas; sobre Conflictos de Leyes en Materia de Letras de Cambio, Pagarés y Facturas; sobre Arbitraje Comercial Internacional; sobre Recepción de Pruebas en el Extranjero; sobre Conflictos de Leyes en Materia de Sociedades Mercantiles; sobre Prueba e Información acerca del Derecho Extranjero; sobre Normas Generales de Derecho Internacional Privado; sobre Personalidad y Capacidad de Personas Jurídicas en el Derecho Internacional Privado. 